\title{
Occurrence and characteristics of mesoscale eddies in the tropical northeastern Atlantic Ocean
}

\author{
Florian Schütte $^{1}$, Peter Brandt ${ }^{1,2}$, and Johannes Karstensen ${ }^{1}$ \\ ${ }^{1}$ GEOMAR Helmholtz Centre for Ocean Research Kiel, Kiel, Germany \\ ${ }^{2}$ Christian-Albrechts-Universität zu Kiel, Kiel, Germany \\ Correspondence to: Florian Schütte (fschuette@geomar.de)
}

Received: 6 November 2015 - Published in Ocean Sci. Discuss.: 18 December 2015

Revised: 26 April 2016 - Accepted: 27 April 2016 - Published: 13 May 2016

\begin{abstract}
Coherent mesoscale features (referred to here as eddies) in the tropical northeastern Atlantic Ocean (between $12-22^{\circ} \mathrm{N}$ and $15-26^{\circ} \mathrm{W}$ ) are examined and characterized. The eddies' surface signatures are investigated using 19 years of satellite-derived sea level anomaly (SLA) data. Two automated detection methods are applied, the geometrical method based on closed streamlines around eddy cores, and the Okubo-Weiß method based on the relation between vorticity and strain. Both methods give similar results. Mean eddy surface signatures of SLA, sea surface temperature (SST) and sea surface salinity (SSS) anomalies are obtained from composites of all snapshots around identified eddy cores. Anticyclones/cyclones are identified by an elevation/depression of SLA and enhanced/reduced SST and SSS in their cores. However, about $20 \%$ of all anticyclonically rotating eddies show reduced SST and reduced SSS instead. These kind of eddies are classified as anticyclonic mode-water eddies (ACMEs). About $146 \pm 4$ eddies per year with a minimum lifetime of 7 days are identified (52\% cyclones, 39\% anticyclones, $9 \%$ ACMEs) with rather similar mean radii of about $56 \pm 12 \mathrm{~km}$. Based on concurrent in situ temperature and salinity profiles (from Argo float, shipboard, and mooring data) taken inside of eddies, distinct mean vertical structures of the three eddy types are determined. Most eddies are generated preferentially in boreal summer and along the West African coast at three distinct coastal headland regions and carry South Atlantic Central Water supplied by the northward flow within the Mauretanian coastal current system. Westward eddy propagation (on average about $3.00 \pm 2.15 \mathrm{~km} \mathrm{~d}^{-1}$ ) is confined to distinct zonal corridors with a small meridional deflection dependent on the eddy type (anticyclones - equatorward, cyclones - pole-
\end{abstract}

ward, ACMEs - no deflection). Heat and salt fluxes out of the coastal region and across the Cape Verde Frontal Zone, which separates the shadow zone from the ventilated subtropical gyre, are calculated.

\section{Introduction}

The generation of eddies in coastal upwelling regions is strongly related to the eastern boundary circulation and its seasonal variations. Within the tropical Atlantic Ocean off northwestern Africa (TANWA; 12 to $22^{\circ} \mathrm{N}$ and 26 to $15^{\circ} \mathrm{W}$ ), the large-scale surface circulation responds to the seasonal variability of the trade winds and the north-south migration of the Intertropical Convergence Zone (ITCZ) (e.g., Stramma and Isemer, 1988; Siedler et al., 1992; Stramma and Schott, 1999). The seasonal wind pattern results in a strong seasonality of the flow field along the northwestern African coast and in coastal upwelling of different intensity. The coastal upwelling in the TANWA is mainly supplied by water masses of South Atlantic origin (Jones and Folkard, 1970; Hughes and Burton, 1974; Wooster et al., 1976; Mittelstaedt, 1991; OuldDedah et al., 1999; Pastor et al., 2008; Glessmer et al., 2009; Peña-Izquierdo et al., 2015), which are relatively cold and fresh compared to the North Atlantic waters further offshore. The water mass transition region coincides with the eastern boundary shadow zone, where diffusive transport pathways dominate (Luyten et al., 1983) with weak zonal current bands superimposed (Brandt et al., 2015). The oceanic circulation in the TANWA is most of the time weak and the velocity field is dominated by cyclonic and anticyclonic eddies. However, global as well as regional satellite-based studies of eddy 
distribution and characterization (Chelton et al., 2007, 2011; Chaigneau et al., 2009) found high eddy activity in terms of eddy generation in the TANWA, but only rare occurrence of long-lived eddies (> 112 days referred to Chelton et al., 2007, $>35$ days, referred to Chaigneau et al., 2009). Karstensen et al. (2015) studied individual energetic eddy events based on a combination of in situ and satellite-based sea level anomaly (SLA) data, and reported eddy life times of more than 200 days in the TANWA region. These individual eddies carried water mass characteristics typical for the shelf region up to $900 \mathrm{~km}$ off the African coast. One possible generation area for such eddies is the Cap-Vert headland at about $14.7^{\circ} \mathrm{N}$ near the Senegalese coast (Karstensen et al., 2015). Analyzing surface drifter data and high-resolution satellite data, Alpers et al. (2013) described the evolution of an energetic sub-mesoscale eddy at the Cap-Vert headland that was presumably generated by flow separation of a wind-forced coastal jet. Earlier studies reported on the importance of eddy transport in the TANWA region (e.g., Hagen, 1985; Barton, 1987; Zenk et al., 1991). However, characteristics of the eddy field in the TANWA region such as seasonality in eddy generation, eddy lifetime, vertical structure, or frequency of occurrence are so far undocumented.

More comprehensive information on eddy dynamics was gained for the Pacific Ocean eastern boundary upwelling systems. The eddy generation in the northeastern Pacific Ocean, off California and Mexico including the California Current System, was studied with high-resolution models applied to reproduce observed characteristics of the eddy field (Liang et al., 2012; Chang et al., 2012). These studies not only highlight hotspots of eddy generation associated with local wind fluctuations (e.g., over the Gulf of Tehuantepec and Papagayo), but also suggest an important role of lowfrequency wind and boundary forcing. For the southeastern Pacific Ocean, off Peru and Chile, including the Peru-Chile Current System, Chaigneau et al. $(2008,2011)$ analyzed the seasonal to interannual variability of eddy occurrence as well as the mean vertical structure of eddies based on Argo floats.

A schematic of the current system of the TANWA in boreal spring and in boreal autumn is presented in Fig. 1. In the north of the TANWA the Canary Current (CC) transports cold water southwards along the African shelf. It detaches from the coast around Cap Blanc (more specifically at about $20^{\circ} \mathrm{N}$ during spring and $25^{\circ} \mathrm{N}$ during autumn) and joins the North Equatorial Current (NEC) (Mittelstaedt, 1983, 1991). The dominant feature south of the TANWA is the eastward flowing North Equatorial Countercurrent (NECC) extending over a latitudinal range from $3^{\circ} \mathrm{N}$ to about $10^{\circ} \mathrm{N}$. It has a pronounced seasonal cycle with maximum strength in boreal summer and autumn, when the ITCZ reaches its northernmost position. During that period the NECC is a continuous zonal flow across the entire tropical Atlantic (e.g., Garzoli and Katz, 1983; Richardson and Reverdin, 1987; Stramma and Siedler, 1988; Polonsky and Artamonov, 1997). When approaching the African coast, the current is partly de- flected to the north feeding a sluggish northward flow along the coast. This current is referred to as Mauretania Current (MC) and reaches latitudes up to $20^{\circ} \mathrm{N}$ (Mittelstaedt, 1991). The strength of the MC is strongly related to the seasonally varying NECC with a time lag of 1 month (Lázaro et al., 2005). During boreal winter and spring when the NECC is pushed to the Equator and becomes unstable, the MC becomes weak and unsteady and only reaches latitudes south of Cap-Vert (Mittelstaedt, 1991; Lázaro et al., 2005). During this period the wind induced coastal upwelling is at its maximum. Simultaneously, the large-scale pressure gradient set by the southward winds induces an along-slope subsurface current, known as Poleward Undercurrent (PUC) (Barton, 1989). During boreal summer the MC re-establishes contemporaneously to the suppression of coastal upwelling south of Cap Blanc at $21^{\circ} \mathrm{N}$ (Peña-Izquierdo et al., 2012).

The eastern boundary upwelling is supplied by waters of South Atlantic origin through a pathway consisting of the North Brazil Current (NBC), the North Equatorial Undercurrent (NEUC) and the PUC. Hence, the purest South Atlantic Central Water (SACW) within the TANWA is found close to the coast (Fig. 2), while further offshore a transition towards the more saline and warmer North Atlantic Central Water (NACW) is observed. The boundary between the regimes is associated with the Cape Verde Frontal Zone (CVFZ; Fig. 2), characterized by a sharp horizontal salinity gradient of 0.9 per $10 \mathrm{~km}$ (Zenk et al., 1991). In this study, salinities are reported dimensionless, defined by the UNESCO Practical Salinity Scale of 1978 (PSS-78). The efficiency of mesoscale eddies to transport cold and less saline SACW from their generation regions near the coast into the open ocean where NACW dominates is one topic investigated in this paper. In particular, the characteristics of these eddies (size, structure, frequency) and their potential role in the transport of heat and salt will be examined in more detail.

The paper is organized as follows: in Sect. 2, the different data types (satellite derived and in situ) will be introduced as well as the techniques to automatically detect and track eddies from satellite data and to derive their vertical structure. In Sect. 3 the eddy characteristics (origin, pathways, surface signature) and statistics (frequency) are discussed and the temporal and spatial variability of eddy generation and eddy pathways are examined. The mean horizontal and vertical eddy structures are derived and, in combination with the eddy statistics, used to estimate the transport of volume, heat, and salt from the shelf region into the open ocean. Finally our results are summarized in Sect. 4. 

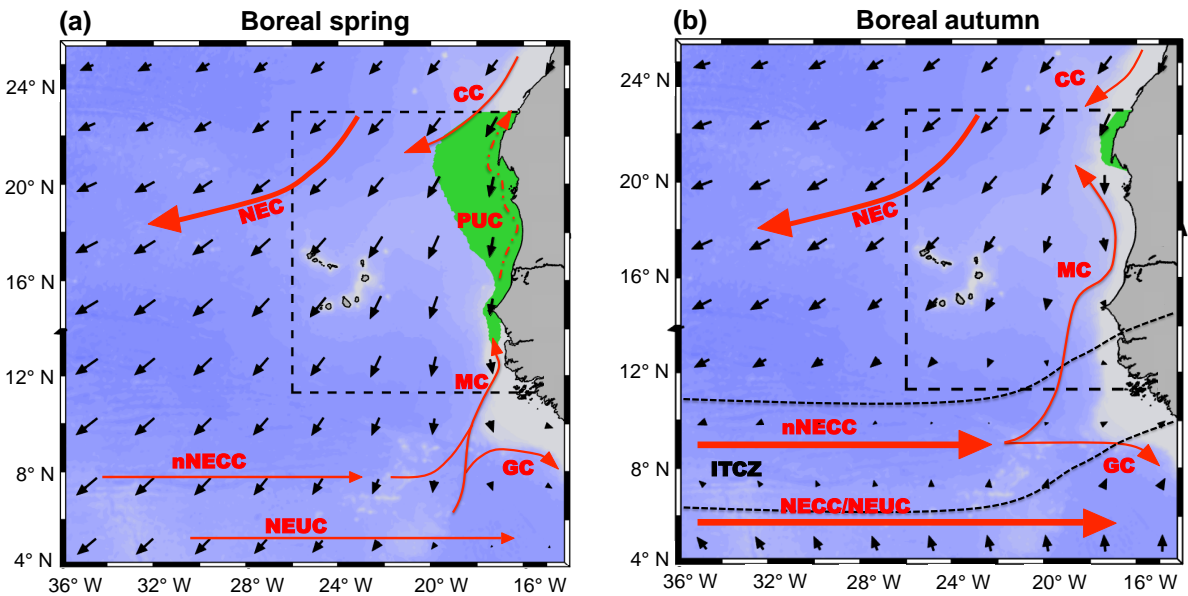

Figure 1. Schematic of the current system of the eastern tropical North Atlantic (red arrows; North Equatorial Current (NEC), Canary Current (CC), Poleward Undercurrent (PUC), Mauretania Current (MC), North Equatorial Countercurrent (NECC), Guinea Current (GC), North Equatorial Undercurrent (NEUC)) (a) in boreal spring and (b) in boreal autumn. Black arrows are mean wind vectors, green areas indicate seasonal mean SST $<21^{\circ} \mathrm{C}$. Blue colors represent topography and the dashed box indicates the TANWA area. The mean position of the Intertropical Convergence Zone (ITCZ) in autumn is indicated as the region bounded by the two black dashed lines in (b).

(a)

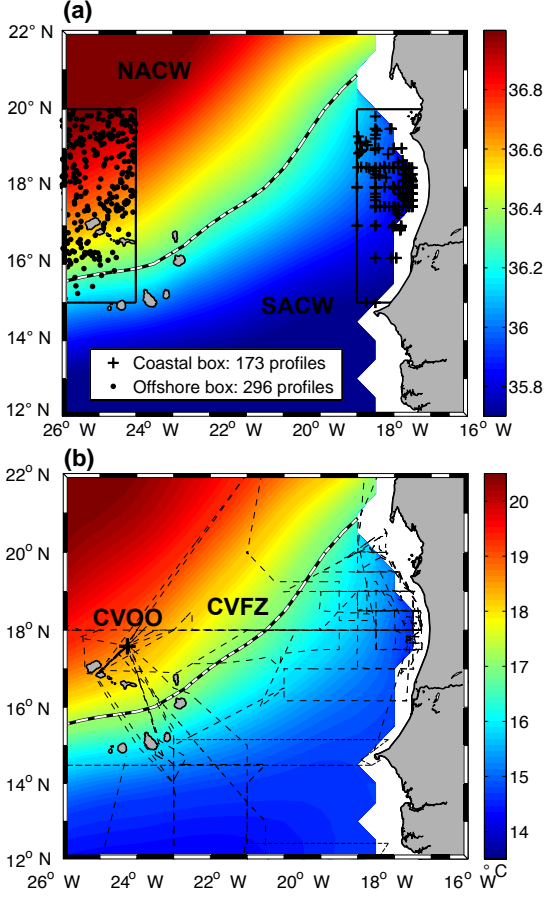

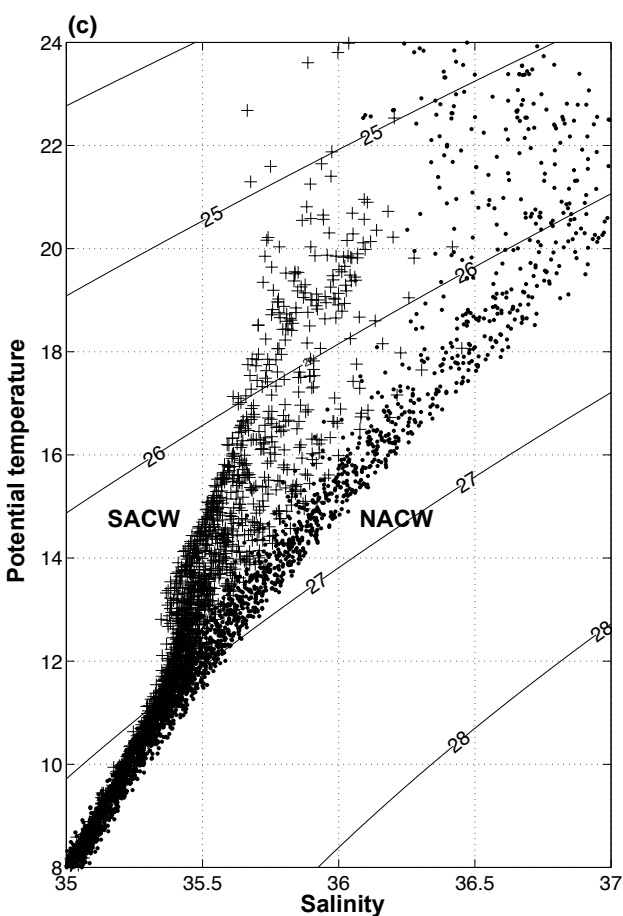

Figure 2. Mean salinity (a) and potential temperature (b) at $100 \mathrm{~m}$ depth in the TANWA from the monthly, isopycnal/mixed-layer ocean (MIMOC) climatology (Schmidtko et al., 2013) and $\theta / S$ diagram (c). The thick black/white line in (a) and (b) indicates the CVFZ. In (a) crosses and dots represent all available profiles (from Argo floats and ships) in the marked coastal and offshore boxes, respectively. In (c), the thin dashed line mark cruise tracks of 20 research cruises to the TANWA taking profiles used in the present study. The black cross in (b) indicates the position of the Cape Verde Ocean Observatory (CVOO) mooring. In (c) data from the coastal and offshore boxes are marked by crosses and dots, respectively; superimposed are isolines of potential density. 


\section{Data and methods}

\subsection{Satellite data}

\subsubsection{SLA, SST, and SSS}

The delayed-time reference data set "all-sat-merged" of SLA (Version 2014), which is used in the study, is produced by Ssalto/Duacs and distributed by AVISO (Archiving, Validation, and Interpretation of Satellite Oceanographic), with support from CNES (http://www.aviso.altimetry.fr/duac/). The data are a multi-mission product, mapped on a $1 / 4^{\circ} \times$ $1 / 4^{\circ}$ Cartesian grid and has a daily temporal resolution. The anomalies are computed with respect to a 20 -year mean. Data for the period January 1995 to December 2013 are considered here. Geostrophic velocity anomalies derived from the SLA provided by AVISO for the same timespan are also used in this study. Given the interpolation technique applied to the along track SLA data Gaussian shaped eddies with a radius $>\sim 45 \mathrm{~km}$ can be detected; eddies of smaller diameter may be detected but their energy is damped (Fu and Ferrari, 2008).

For sea surface temperature (SST) the data set "Microwave Optimally interpolated Sea Surface Temperature" from Remote Sensing Systems (www.remss.com) is used. It is derived from satellite microwave radiometers, which have the capability to measure through clouds. It has a $25 \mathrm{~km}$ resolution and contains the SST measurements from all operational radiometers for a given day. All SST values are corrected using a diurnal model to create a foundation SST that represents a 12:00 LT temperature (www.remss.com). Daily data from the outset (1 January 1998 to 31 December 2013) are used here and mapped similar to the SLA data on a $1 / 4^{\circ} \times 1 / 4^{\circ}$ Cartesian grid.

Our study also includes sea surface salinity (SSS) data. We make use of the LOCEAN_v2013 SSS product available from 1 January 2010 until the end of our analysis period (31 December 2013). The data are distributed by the Ocean Salinity Expertise Center (CECOS) of the Centre National d'Etudes Spatiales (CNES) - Institut Français de Recherche pour l'Exploitation de la Mer (IFREMER) Centre Aval de Traitemenent des Donnees SMOS (CATDS), at IFREMER, Plouzane (France). The data are created using the weight averaging method described in Yin et al. (2012) and the flag sorting described in Boutin et al. (2013). Finally the data are mapped on a $1 / 4^{\circ} \times 1 / 4^{\circ}$ Cartesian grid and consist of 10 day composites.

\subsubsection{Eddy identification and tracking from satellite data}

In order to detect eddy-like structures, two different methods are applied to the SLA data. The first method, the Okubo-Weiß method (OW method; Okubo, 1970; Weiss, 1991), has been frequently used to detect eddies using satel- lite data as well as the output from numerical studies (e.g., Isern-Fontanet et al., 2006; Chelton et al., 2007; Sangrà et al., 2009). The basic assumption behind the OW method is that regions, where the relative vorticity dominates over the strain, i.e., where rotation dominates over deformation, characterize an eddy. In order to separate strong eddies from the weak background flow field a threshold needs to be identified. For this study the threshold is set to $W_{0}=-0.2 \times \sigma$, where $\sigma$ is the spatial standard derivation of the Okubo-Weiß parameter $W=s_{\mathrm{n}}^{2}+s_{\mathrm{s}}^{2}-\omega^{2}$. Here, $s_{\mathrm{n}}=\frac{\partial u}{\partial x}-\frac{\partial v}{\partial y}$ is the normal strain, $s_{\mathrm{S}}=\frac{\partial v}{\partial x}+\frac{\partial u}{\partial y}$ is the shear strain and $\omega=\frac{\partial v}{\partial x}-\frac{\partial u}{\partial y}$ is the relative vorticity. A similar definition of the threshold was used in other eddy studies applying the OW method (e.g., Chelton et al., 2007). The maximum (minimum) SLA marks the eddy center.

The second method for eddy detection is based on a geometric approach (in the following GEO method) analyzing the streamlines of the SLA-derived geostrophic flow. An eddy edge is defined as the streamline with the strongest swirl velocity around a center of minimum geostrophic velocity (Nencioli et al., 2010). For the detection of an eddy, the algorithm requires two parameters $a$ and $b$ to be defined. The first parameter, $a$, is a search radius in grid points. Inside the search radius, the velocity reversal across the eddy center is identified ( $v$ component on an east-west section, $u$ component on a north-south section). The second parameter, $b$, is used to identify the point of minimum velocity within a region that extends up to $b$ grid points (for a more detailed description of the method see Nencioli et al., 2010). After a few sensitivity tests in comparison with the results of the OW method and following the instructions of Nencioli et al. (2010), we set $a=3$ and $b=2$. Optimal results were obtained when we linearly interpolated the AVISO velocity fields onto a $1 / 6^{\circ} \times 1 / 6^{\circ}$ grid before we applied the algorithm (for more information see also Liu et al., 2012). If an eddy is detected, then an eddy center is identified in analogy to the OW method as the maximum (anticyclone) or the minimum (cyclone) of SLA within the identified eddy structure.

When applying the two different eddy detection methods to the SLA data from the TANWA region, we used the same eddy detection thresholds for both methods; i.e., a feature only counts as an eddy, if its radius is larger than $45 \mathrm{~km}$ and it is detectable for a period of more than 7 days. Note, as the identified eddy areas are rarely circular we used the circleequivalent of the area of the detected features to estimate the radius. For eddy tracking both eddy detection methods use the same tracking algorithm. An eddy trajectory was calculated if an eddy with the same polarity was found in at least 7 consecutive SLA maps (corresponding to 1 week) within a search radius of up to $50 \mathrm{~km}$. Due to, e.g., errors in SLA mappings (insufficient altimetric coverage) an eddy could vanish and re-emerge after a while. Therefore we searched in 14 consecutive SLA maps (corresponding to 2 weeks) in a search radius of up to $100 \mathrm{~km}$ after an eddy disappearance, if 
eddies with the same polarity re-emerges. If more than one eddy with the same polarity emerge within the search radius, we defined the following similarity parameter to discriminate between these eddies:

$X=\sqrt{\left(\frac{\text { distance }}{100}\right)^{2}+\left(\frac{\Delta \text { radius }}{\text { radius }_{0}}\right)^{2}+\left(\frac{\Delta \text { vorticity }}{\text { vorticity }_{0}}\right)^{2}+\left(\frac{\Delta \mathrm{EKE}}{\mathrm{EKE}_{0}}\right)^{2}}$,

which include four terms based on the distance between the disappeared and newly emerged eddies and the difference of their radii, mean vorticity, and mean eddy kinetic energy (EKE). Radius 0 , vorticity 0 , and $\mathrm{EKE}_{0}$ are the mean radius, vorticity and EKE of all identified eddies in TANWA. The newly emerged eddy with the smallest $x$ is selected to be the same eddy. To give an idea of the uncertainty related to the detection technique, both methods are applied to the data. Every step is computed separately with both methods and the results are compared.

\subsubsection{Eddy classification and associated mean spatial surface pattern}

From the geostrophic velocity data, anticyclones (cyclones) can be identified due to their negative (positive) vorticity. In the SLA data anticyclones (cyclones) are associated with a surface elevation (depression). The maximum (minimum) SLA marks the eddy center. In general, anticyclones (cyclones) carry enhanced (reduced) SST and enhanced (reduced) SSS in their cores, respectively. However, we found that $20 \%$ of all detected anticyclones had cold anomalies in their cores and a reduced SSS. This kind of eddies is classified as an anticyclonic mode-water eddy (ACME) or intrathermocline eddy (Kostianoy and Belkin, 1989) as will later be confirmed when considering the in situ observations (see below). Given that ACMEs show distinct characteristics, which are contrasting to anticyclones (see below), we distinguish in the following three types of eddies: anticyclones, cyclones, and ACMEs.

Composites of satellite-derived SST and SSS anomalies with an extent of $300 \mathrm{~km} \times 300 \mathrm{~km}$ around the eddy centers yield the mean spatial eddy surface pattern of temperature and salinity for the respective eddy type. The information whether an eddy is cold/warm or fresh/saline in the core is obtained by subtracting the average value over the edge of the box from the average value over the eddy center and its closest neighboring grid points. To exclude large-scale variations in the different data sets, the SST and SSS fields are low-pass filtered with cutoff wavelength of $15^{\circ}$ longitude and $5^{\circ}$ latitude. Thereafter the filtered data sets are subtracted from the original data sets thus preserving the mesoscale variability. The composite plots are based only on eddies with a radius between 45 and $70 \mathrm{~km}$ and an absolute SLA difference between the eddy center and the mean along the edge of the $300 \mathrm{~km} \times 300 \mathrm{~km}$ box used for the composites greater than $2 \mathrm{~cm}$.

\subsection{In situ data}

\subsubsection{Argo floats}

A set of irregular distributed vertical CTD (conductivitytemperature-depth) profiles was obtained from the autonomous profiling floats of the Argo program. The freely available data were downloaded from the Global Data Assembly Centre in Brest, France (www.argodatamgt.org) and encompasses the period from July 2002 to December 2013. Here only pressure $(P)$, temperature $(T)$, and salinity $(S)$ data flagged with Argo quality category 1 are used. The given uncertainties are $\pm 2.4 \mathrm{dbar}$ for pressure, $\pm 0.002{ }^{\circ} \mathrm{C}$ for temperature, and \pm 0.01 for uncorrected salinities. In most cases the salinity errors are further reduced by the delayed-mode correction. For this analysis an additional quality control is applied in order to eliminate spurious profiles and to ensure good data quality in the upper layers. In the following, we give the criteria applied to the Argo float profiles and in brackets the percentage, to which the criteria were fulfilled. Selected profiles must (i) include data between 0 and $10 \mathrm{~m}$ depth $(98.2 \%)$, (ii) have at least 4 data points in the upper $200 \mathrm{~m}(98.8 \%)$, (iii) reach down to $1000 \mathrm{~m}$ depths $(95 \%)$, with (iv) continuous and consistent temperature, salinity, and pressure data $(78 \%)$. This procedure reduced the number of profiles by around $30 \%$ to 2022 Argo float profiles for the TANWA.

\subsubsection{Shipboard measurements}

In situ CTD profile data collected during 20 ship expeditions to the TANWA within the framework of different programs are used (Fig. 2b; see Table 1 for further details). In total 579 profiles were available taken within the TANWA during the period March 2005 to June 2013. Data sampling and quality control followed the standards set by Global Ocean Ship-Based Hydrographic Investigations Program (GO-SHIP) (Hood et al., 2010). However, we assume a more conservative accuracy of our shipboard data of about twice the GO-SHIP standard, which is $\pm 0.002^{\circ} \mathrm{C}$ and \pm 0.004 for temperature and salinity, respectively.

\subsubsection{CVOO mooring}

The third set of in situ data stems from the Cape Verde Ocean Observatory (CVOO) mooring. The CVOO mooring is a deep-sea mooring deployed at a depth of about $3600 \mathrm{~m}, 60 \mathrm{~km}$ northeast of the Cabo Verdean island of São Vicente (Fig. 2b). The nominal mooring position is $17^{\circ} 36^{\prime} \mathrm{N}$, $24^{\circ} 15^{\prime} \mathrm{W}$. The mooring was first deployed in June 2006 and has been redeployed in March 2008, October 2009, May 2011, and October 2012. Temperature and salinity measurements in the upper $400 \mathrm{~m}$ have been typically recorded at depth of $30,50,70,100,120,200,300$, and $400 \mathrm{~m}$ using MicroCAT instruments. Data calibration is done against ship- 
Table 1. Data from the following research cruises were used.

\begin{tabular}{|c|c|c|c|c|}
\hline Cruise & Ship & Time & Region & $\begin{array}{r}\text { No. of } \\
\text { profiles }\end{array}$ \\
\hline Pos 320 & Poseidon & Mar-Apr 2005 & TANWA East & 38 \\
\hline M 68/2 & Meteor & Jul 2006 & $23^{\circ} \mathrm{W}$ Section & 10 \\
\hline M 68/3 & Meteor & Jul-Aug 2006 & $18^{\circ} \mathrm{N}$ Section & 81 \\
\hline Pos 347 & Poseidon & Jan-Feb 2007 & TANWA East & 125 \\
\hline Pos 348 & Poseidon & Feb 2007 & TANWA East & 32 \\
\hline Ata 3 & L'Atalante & Feb 2008 & TANWA East & 58 \\
\hline Ata 4 & L'Atalante & Mar 2008 & $23^{\circ} \mathrm{W}$ Section & 6 \\
\hline MSM 8 & Maria S. Merian & May 2008 & South TANWA & 3 \\
\hline MSM 10 & Maria S. Merian & Dec 2008 & South TANWA & 5 \\
\hline Pos 399 & Poseidon & May-Jul 2009 & TANWA East & 21 \\
\hline M 80/1 & Meteor & Nov 2009 & $23^{\circ} \mathrm{W}$ Section & 9 \\
\hline M 80/2 & Meteor & Dec 2009 & South TANWA & 8 \\
\hline M 81/1 & Meteor & May 2010 & Central TANWA & 12 \\
\hline M 83/1 & Meteor & Dec 2010 & $14.5^{\circ} \mathrm{N}$ Section & 27 \\
\hline MSM 18/2 & Maria S. Merian & May 2011 & $23^{\circ} \mathrm{W}$ Section & 6 \\
\hline MSM $18 / 3$ & Maria S. Merian & Jun 2011 & South TANWA & 6 \\
\hline MSM 22 & Maria S. Merian & Nov 2012 & $18^{\circ} \mathrm{N}$ Section & 76 \\
\hline MSM 23 & Maria S. Merian & Nov 2012 & $14.5^{\circ} \mathrm{N}$ Section & 13 \\
\hline M 96 & Meteor & May 2013 & $14.5^{\circ} \mathrm{N}$ Section & 14 \\
\hline M 97 & Meteor & Jun 2013 & $14.5^{\circ} \mathrm{N}$ Section & 7 \\
\hline
\end{tabular}

board CTD data during the service cruises. The uncertainties are $\pm 0.002^{\circ} \mathrm{C}$ for temperature and \pm 0.01 for salinity.

The eddy detection method identifies 22 eddies passing the CVOO mooring. For these eddy events, the original time series with a temporal resolution of 15 or 20 min were lowpass filtered with a cutoff period of $24 \mathrm{~h}$ and consecutively subsampled to 1-day values in order to reduce instrument noise and to match the resolution of the SLA maps. In total 429 profiles could be obtained. $T / S$ (temperature/salinity) anomaly profiles were derived as the difference of profiles inside and outside of the eddies. The outside profiles were taken shortly before the eddy passage.

\subsection{Determining the vertical structure of eddies detected in SLA data}

In order to investigate the vertical structure of eddies identified in SLA data, a combination of all available in situ data sets was used. We had a total of 3030 CTD profiles available for the time period 2002 to 2013, with about $67 \%$ Argo float profiles, $19 \%$ shipboard CTD profiles, and $14 \%$ mooringbased profiles (Fig. 3). All profiles were vertically interpolated or re-gridded to $1 \mathrm{~m}$ vertical resolution in the depth range 5 to $1000 \mathrm{~m}$. Missing data points within the first few meters of the water column were filled by constant extrapolation. For each profile, we determined the mixed layer depth (MLD) as the depth where the in situ temperature decreased by $0.2^{\circ} \mathrm{C}$ relative to $10 \mathrm{~m}$ depth (de Boyer Montégut et al., 2004).

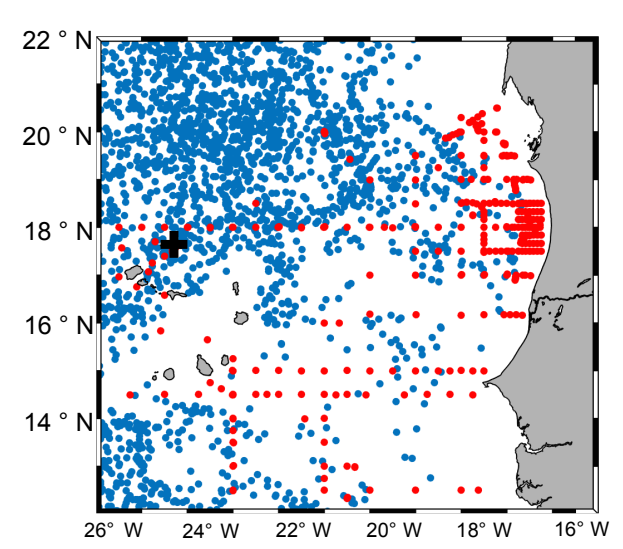

Figure 3. Locations of available temperature and salinity profiles obtained in the TANWA between 1995 and 2013. Red dots mark shipboard CTD stations, blue dots locations of Argo float profiles, and the black cross the location of the CVOO mooring.

By co-location, in space and time, of eddies, which are identified in the SLA data using a combination of the OW and the GEO method (an eddy has to be identified by both algorithms), with the combined in situ data set, the vertical structures of anticyclones and ACMEs (positive SLA) and cyclones (negative SLA) were assessed (Fig. 4). The classification results in 675 profiles taken in anticyclones/ACMEs, 499 profiles taken in cyclones, and 1856 profiles taken outside of detected eddies. Excluding the mooring-based pro- 
(a)

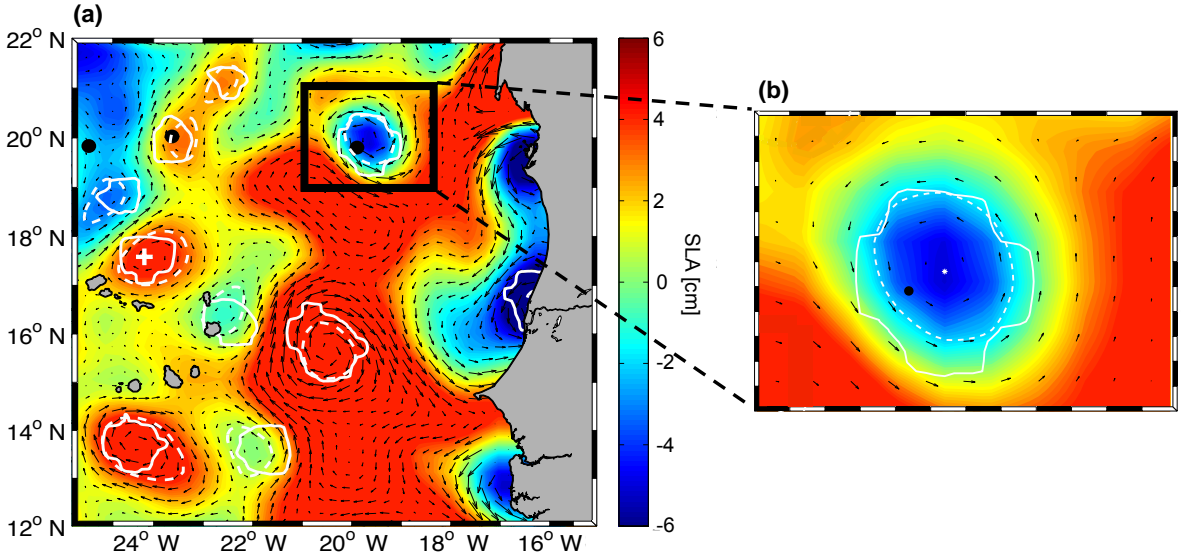

Figure 4. Snapshot of the SLA for 22 December 2010, with the results of the eddy-detection methods: OW method (solid white line) and the GEO method (dashed white line) with geostrophic velocities superimposed (black arrows). The black dots mark Argo float profiles, the white cross in (a) indicates the CVOO mooring. In (b) a zoom of a selected region with a cyclonic eddy is shown.

files, from which we only extracted eddy events, around $\sim 29 \%$ of all profiles (Argo float and shipboard CTD profiles) were taken coincidentally inside of an eddy. This proportion is in the range of earlier results derived by Chaigneau et al. (2011), who estimated that $\sim 23 \%$ of their Argo float profiles in the eastern upwelling regions of the Pacific Ocean are conducted in eddies and Pegliasco et al. (2015), who found $38 \%$ of all their Argo float profiles in the eastern upwelling areas conducted in eddies. We could also confirm with the result of Pegliasco et al. (2015) that the majority of all Argo float profile in eddies are conducted in long-lived anticyclones/ACMEs.

However, we are interested in the anomalous water mass characteristic inside the eddy compared to the surrounding water. Anomaly profiles of potential temperature, $\theta$, salinity, $S$, and potential density, $\sigma_{\theta}$, were derived as the difference of the profiles inside and reference profiles outside of an eddy. Profiles outside of eddies are required to be taken within a maximum distance of $120 \mathrm{~km}$ from the eddy center and at maximum \pm 25 days apart from the time the profile inside of the eddy was taken (Fig. 4). For 176 profiles out of the 1174 profiles inside of eddies, no reference profile could be found fulfilling these criteria. In total 587 anomaly profiles for anticyclones/ACMEs and 411 anomaly profiles for cyclones were derived. As mentioned before it was useful to further separate anticyclonically rotating eddies into two types: conventional anticyclones with downward bending isopycnals (and isotherms) throughout and ACMEs with upward bending isopycnals in the upper 50 to $100 \mathrm{~m}$ depth and downward bending isopycnals below. As a consequence, the MLD inside the ACMEs is shallower compared to background values, while it can be several tens of meters deeper in conventional anticyclones. We used the MLD difference to proof the separation into conventional anticyclones and ACMEs from the satellite-based surface signatures, described above. In all cases, where the MLD inside of an anticyclonically rotating eddy was at least $10 \mathrm{~m}$ shallower than the MLD outside the eddy, the eddy was associated with a negative SST anomaly. Hence, the eddy-type separation through satellite-based surface signatures appears to be accurate. The separation identified 95 out of 587 profiles in anticyclonically rotating eddies as being taken in ACMEs (Fig. 5). Averaging all anomaly profiles for anticyclones, cyclones, and ACMEs yields mean anomaly profiles for potential temperature, $\overline{\theta^{\prime}}$, salinity, $\overline{S^{\prime}}$, and potential density, $\overline{\sigma_{\theta}^{\prime}}$, for the three different eddy types. Profiles of available heat and salt anomalies available heat anomalies (AHA $\left[\mathrm{J} \mathrm{m}^{-1}\right]$ ) and available salt anomalies (ASA $\left.\left[\mathrm{kg} \mathrm{m}^{-1}\right]\right)$ per meter on the vertical were then derived as

$$
\begin{aligned}
& \mathrm{AHA}=\pi r^{2} \rho C_{p} \overline{\theta^{\prime}}, \\
& \mathrm{ASA}=0.001 \times \pi r^{2} \rho \overline{S^{\prime}},
\end{aligned}
$$

where $\rho$ is density (in $\mathrm{kg} \mathrm{m}^{-3}$ ), $C_{\mathrm{p}}$ is specific heat capacity $\left(4186.8 \mathrm{~J} \mathrm{~kg}^{-1} \mathrm{~K}^{-1}\right)$, and $r$ is the mean radius. The factor 0.001 in Eq. (2) is an approximation to convert PSS-78 salinity to salinity fractions ( $\mathrm{kg}$ of salt per $\mathrm{kg}$ of seawater). These calculations are partly adapted from Chaigneau et al. (2011), where AHA and ASA are computed for eddies in the eastern Pacific. Integrating AHA and ASA per meter over the depth range 0 to $350 \mathrm{~m}$, the $\mathrm{AHA}_{\text {total }}$ (in J) and $\mathrm{ASA}_{\text {total }}$ (in $\mathrm{kg}$ ) was obtained. The lower boundary of integration was chosen as below; $350 \mathrm{~m}$ no significant temperature and salinity anomalies could be identified for the composite eddies of the three eddy types.

Eddies that pinch off from the eastern boundary are expected to carry waters with SACW signature westward into areas where waters with NACW signature prevail. To quantify the amount of SACW carried by these eddies, we follow a method developed by Johns et al. (2003) used to quantify the amount of water of Southern Hemisphere origin carried by North Brazil Current rings. Accordingly the high- 


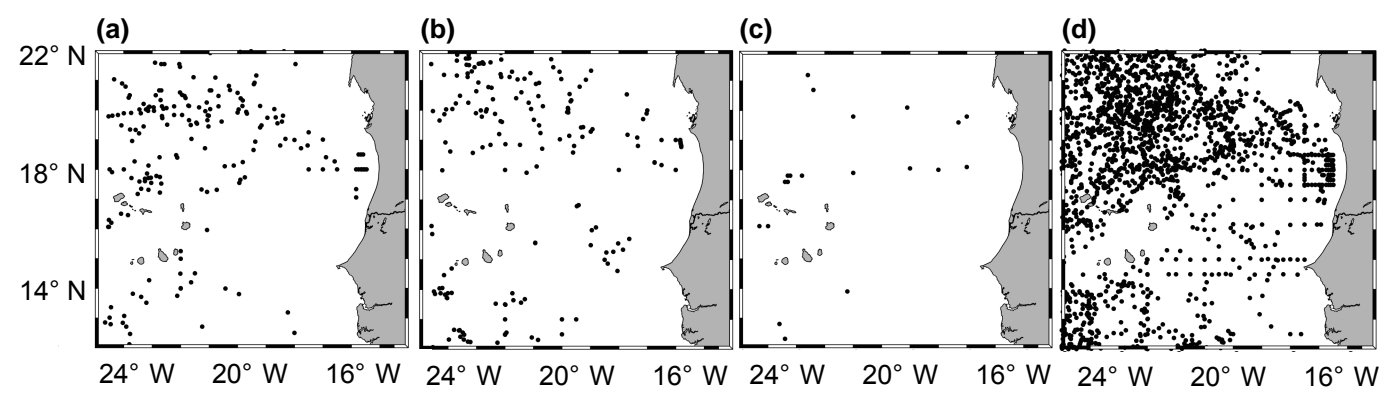

Figure 5. Location of all profiles taken in (a) cyclones, (b) anticyclones, (c) ACMEs, and (d) outside of an eddy.

est/lowest $10 \%$ of the salinity values on potential density surfaces were averaged to define the mean NACW/SACW characteristics in the region as function of potential density. The obtained characteristics were used to determine the percentage of SACW contained in any profile taken inside and outside of eddies. Anomaly profiles of SACW percentage as function of potential density were then calculated as the difference of the profiles inside and outside of eddies and were eventually transformed back into depth space using a mean density profile.

To illustrate mean anomalies in potential temperature, salinity, potential density, and SACW percentage for each eddy type as a function of depth and radial distance, the available profiles were sorted with respect to a normalized distance, which is defined as the actual distance of the profile from the eddy center divided by the radius of the eddy. The profiles were grouped and averaged onto a grid of 0.1 between 0 and 1 of the normalized radial distance. Finally, the field was mirrored at zero distance and a running mean over three consecutive horizontal grid points was applied.

\subsection{Determining the heat, salt, and volume transport}

The three-dimensional structures of composite cyclones, anticyclones, and ACMEs produced out of the combination of altimetry data and all available profiles were used to estimate the relative eddy contribution to fluxes of heat, salt, and volume in the TANWA. Here we chose to define enclosed areas with area I representing the extended boundary current region, area II the transition zone, and area III the subtropical gyre region. By multiplying the heat transport of the composite eddies with the number of eddies dissolving during a year in a given area (corresponding to an flux divergence) a mean heat release (in $\mathrm{W} \mathrm{m}^{-2}$ ) and a mean salt release (in $\mathrm{kg} \mathrm{m}^{-2}$ ) were calculated. The mean heat release can be compared to the net atmospheric heat flux in the area here derived from the NOCS Surface Flux Dataset (Berry and Kent, 2011).

Using the volume of a composite eddy (defined by the mean radius and the depth range 0 to $350 \mathrm{~m}$ ) and the mean SACW percentage within the eddy, the total volume transport of SACW of cyclones, anticyclones, and ACMEs was calculated.
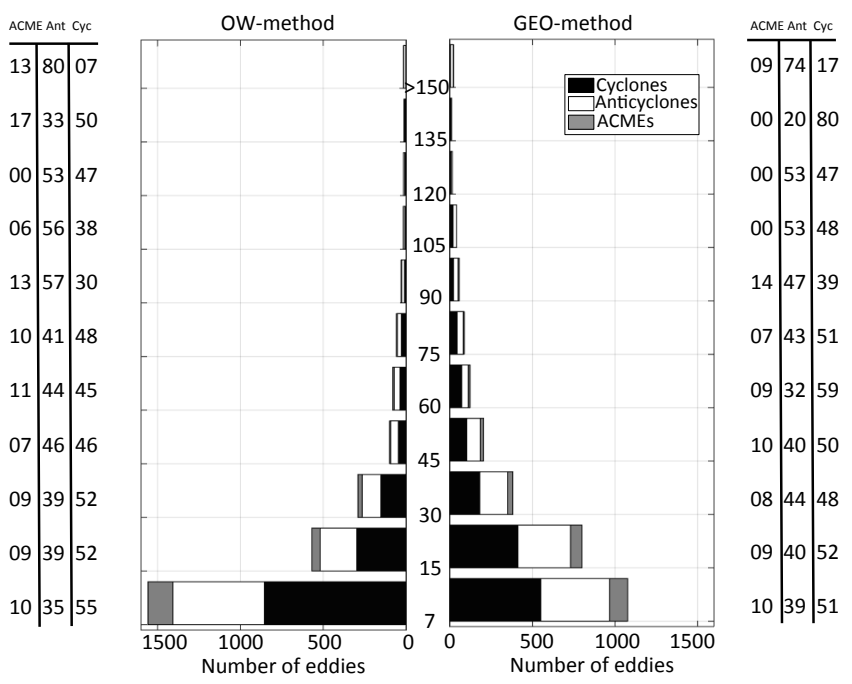

Figure 6. Number of eddies against lifetime in days from the OW method (left) and GEO method (right). Percentage of ACMEs, anticyclones (Ant), and cyclones (Cyc) is given in the tables on the right and left.

\section{Results and discussion}

\subsection{Eddy statistics from SLA data}

The two eddy tracking methods applied to the SLA data detected $\sim 2800$ eddies over the 19 years of analyzed data (Table 2, Fig. 6) with slightly more cyclones than anticyclones/ACMEs $(6 \%$ more in the OW method, $2 \%$ more in the GEO method). Note, that the given number of eddies must be seen as a lower limit due to the coarse resolution of the satellite products. All of the detected eddies are nonlinear by the metric $U / c$, where $U$ is the maximum circumpolar geostrophic surface velocity and $\mathrm{c}$ is the translation speed of the eddy. A value of $U / c>1$ implies that fluid is trapped within the eddy interior (Chelton et al., 2011) and exchange with the surrounding waters is reduced. Many of the eddies are even highly nonlinear, with $60 \%$ having $U / c>5$ and $4 \%$ having $U / c>10$. 
Table 2. Mean properties of anticyclones, cyclones, and ACMEs in the region of $12-22^{\circ} \mathrm{N}, 16-26^{\circ} \mathrm{W}$ (TANWA) and their standard deviation given in brackets, detected from the OW method and the GEO method (detectable longer than 1 week and with a radius $>45 \mathrm{~km}$ ). Coastal area is defined as an $\sim 250 \mathrm{~km}$ wide corridor near the coast (see Fig. 7).

\begin{tabular}{|c|c|c|c|c|c|c|}
\hline $\begin{array}{l}\text { Property } \\
\text { (based on SLA data } \\
\text { between 95-2013) }\end{array}$ & \multicolumn{3}{|c|}{ OW method } & \multicolumn{3}{|c|}{ GEO method } \\
\hline \multirow[t]{3}{*}{ Detected eddies } & \multicolumn{3}{|c|}{$2741\left(144 \mathrm{yr}^{-1}\right)$} & \multicolumn{3}{|c|}{$2816\left(148 \mathrm{yr}^{-1}\right)$} \\
\hline & Anticyclones & Cyclones & ACMEs* & Anticyclones & Cyclones & ACMEs* \\
\hline & $\begin{array}{l}1041 \\
(38 \%)\end{array}$ & $\begin{array}{l}1443 \\
(53 \%)\end{array}$ & $\begin{array}{l}257 \\
(9 \%)\end{array}$ & $\begin{array}{l}1137 \\
(40 \%)\end{array}$ & $\begin{array}{l}1422 \\
(51 \%)\end{array}$ & $\begin{array}{l}257 \\
(9 \%)\end{array}$ \\
\hline $\begin{array}{l}\text { Detected eddies } \\
\text { in coastal area }\end{array}$ & $\begin{array}{l}186 \\
\left(10 \mathrm{yr}^{-1}\right)\end{array}$ & $\begin{array}{l}241 \\
\left(13 \mathrm{yr}^{-1}\right)\end{array}$ & $\begin{array}{l}43 \\
\left(2 \mathrm{yr}^{-1}\right)\end{array}$ & $\begin{array}{l}178 \\
\left(9 \mathrm{yr}^{-1}\right)\end{array}$ & $\begin{array}{l}199 \\
\left(10 \mathrm{yr}^{-1}\right)\end{array}$ & $\begin{array}{l}45 \\
\left(3 \mathrm{yr}^{-1}\right)\end{array}$ \\
\hline Average lifetime (days) & $\begin{array}{l}30( \pm 31) \\
\max 282\end{array}$ & $\begin{array}{l}24( \pm 22) \\
\max 176\end{array}$ & $\begin{array}{l}26( \pm 28) \\
\max 197\end{array}$ & $\begin{array}{l}32( \pm 32) \\
\max 277\end{array}$ & $\begin{array}{l}27( \pm 29) \\
\max 180\end{array}$ & $\begin{array}{l}26( \pm 28) \\
\max 175\end{array}$ \\
\hline Average radius (km) & $53( \pm 5)$ & $51( \pm 5)$ & $52( \pm 5)$ & $60( \pm 20)$ & $62( \pm 22)$ & $59( \pm 20)$ \\
\hline $\begin{array}{l}\text { Average westward } \\
\text { propagation }\left(\mathrm{km} \mathrm{d}^{-1}\right)\end{array}$ & $2.8( \pm 2.4)$ & $2.7( \pm 2.4)$ & $2.8( \pm 2.5)$ & $3.3( \pm 1.8)$ & $3.1( \pm 1.9)$ & $3.3( \pm 1.9)$ \\
\hline
\end{tabular}

* Note, that the properties of ACMEs are based on fewer years of SLA data (1998-2013), due to the unavailable SST data.

Considering only the period after 1998, i.e., when our SST data set becomes available, a satellite data-based separation between anticyclones (positive SST anomalies) and ACMEs (negative SST anomalies) is possible. We found that about $20 \%$ of the anticyclonically rotating eddies are ACMEs. However, the number of ACMEs might be underestimated, because ACMEs are associated with a weak SLA signature and therefore more difficult to detect with the SLA-based algorithms. Also the nonlinearity of ACMEs is underestimated by using geostrophic surface velocity as they have a subsurface velocity maximum.

Although the GEO method in general detects slightly more eddies than the OW method (in total 75 eddies more, which is $2.7 \%$ more than the OW method) the situation is different near the coastal area where the OW method detects 30 eddies per year but the GEO method only 22 eddies per year. This results from the strong meandering of the boundary current, where meanders are sometimes interpreted as eddies by the OW method due to the high relative vorticity. In contrast, the GEO method uses closed streamlines and therefore does not detect meanders as eddies, which makes this method more suitable for eddy detection in coastal areas. The average eddy radius in the TANWA is found to be $56 \pm 12 \mathrm{~km}$ (given here as mean and standard derivation) with the GEO method resulting not only in around $10 \mathrm{~km}$ larger radii but also with a 4 times higher standard deviation when compared with the OW method. The difference in the standard deviation of the eddy radius derived from GEO and the OW method is partly due to the identification of relatively few very large eddies using the GEO method. In general, the OW method appears to be the more reliable tool for identifying the eddy surface area and the corresponding radius in the TANWA.
Both algorithms show that on average the anticyclones and ACMEs are larger and have a longer lifetime than the cyclones. The average westward propagation speed is $3.00 \pm 2.5 \mathrm{~km} \mathrm{~d}^{-1}$ for all eddy types, which is on the order of the first baroclinic mode Rossby wave phase speed at that latitude range (Chelton et al., 1998). The average tracking period (or lifetime) of an eddy in the TANWA is 28 days with a high standard deviation of 28 days. The longest consecutive tracking period for a single eddy (found similar in both algorithms) was around 280 days for an anticyclone, 180 days for a cyclone and 200 days for an ACME. However, most of the eddies were detectable for a period of 7 to 30 days. The number of eddies decreases rapidly with increasing tracking period (Fig. 6). Note that the OW method detects 450 eddies with a lifetime between 7 and 14 days, which is more than the GEO method. However, for longer lifetimes the GEO method detects more eddies than the OW method. As the tracking procedure in both algorithms is the same, the GEO method seems to be more reliable in identifying and following eddy-like structures from one time step to another. The percentage of tracked anticyclones/ACMEs and cyclones is close to $50 \%$ for short tracking periods. For longer lifetimes anticyclonic eddies tend to dominate, this is also reflected in the slightly shorter mean lifetimes of cyclones compared to anticyclones. The dominance of longlived anticyclones is also shown in the observational studies of Chaigneau et al. (2009), Chelton et al. (2011), and theoretically suggested by Cushman-Roisin and Tang (1990). The latter authors showed that in an eddying environment anticyclonic eddies are generally more robust and merge more freely than cyclones producing long-lived eddies, while cyclones show a higher tendency to self-destruction. 
Note, that tracking of eddies in the TANWA is prone to errors in particular regarding the information about the eddies' lifetime. Some eddies disappear in single SLA maps, which is at least partly due to the separation of the satellite ground tracks (Chaigneau et al., 2008). In order to avoid loosing an eddy, we search 2 weeks after its assumed disappearance within a defined radius for an eddy with the same polarity (see Sect. 2.1.2). The fact that purest SACW, which in the TANWA occurs in the eastern boundary region, is found regularly in eddy cores at the CVOO mooring $(\sim 850 \mathrm{~km}$ offshore) (Karstensen et al., 2015) shows that long-lived eddies must exist in the TANWA. Hence, the eddy tracking algorithms underestimate the eddy lifetime and accordingly overestimate the number of newly generated eddies.

This challenge for the eddy tracking algorithms in the TANWA is probably the reason why Chelton et al. (2011) and Chaigneau et al. (2009) could not detect many long-lived eddies in this area. Their definition of long-lived eddies requires eddies to be trackable for longer than 112 days (Chelton et al., 2011) or 35 days (Chaigneau et al., 2009). With the adaption of the method for the TANWA with the 2 weeks search radius as described above, eddy tracking has improved; however, some eddies might still be lost. In addition, the mean eddy lifetime of eddies in TANWA is underestimated due to the restriction of eddy trajectories at the northern, southern, and western boundaries.

\subsection{Generation areas and pathways}

To identify hot spots of eddy generation, the locations of the first detection of each eddy is counted in $1^{\circ} \times 1^{\circ}$ boxes (Fig. 7). The OW method and the GEO method do not show a significantly different pattern, except near the coast, where the local maximum in the number of newly detected eddies is shifted slightly offshore for the GEO method compared to the OW method. However, the distribution shows that most eddies are generated in the coastal area along the shelf. Within this region the headlands of the coast seem to play an important role as about nine newly detected eddies per year are found around Cap-Vert (Senegal), about four eddies per year off Saint-Louis (Senegal) and about five eddies per year off Cap Timris (Mauretania). At these spots the algorithms detect more than $70 \%$ of the newly detected eddies (18 out of 25) per year in the coastal area. Another location of high eddy generation is southeast of the Cabo Verde islands, especially south of the northwesternmost island Santo Antão with about two newly detected eddies per year and southwest of Fogo with about five newly detected eddies per year.

To identify the preferred eddy propagation pathways, the locations of eddy centers, which were tracked for longer than 1 month ( 35 days), were counted in $1 / 6^{\circ} \times 1 / 6^{\circ}$ boxes over all time steps. The spatial distribution of eddy activity indeed shows some structures and eddies tend to move along distinct corridors westward, away from the coast into the open ocean (Fig. 8) as also shown for the Canary Island region

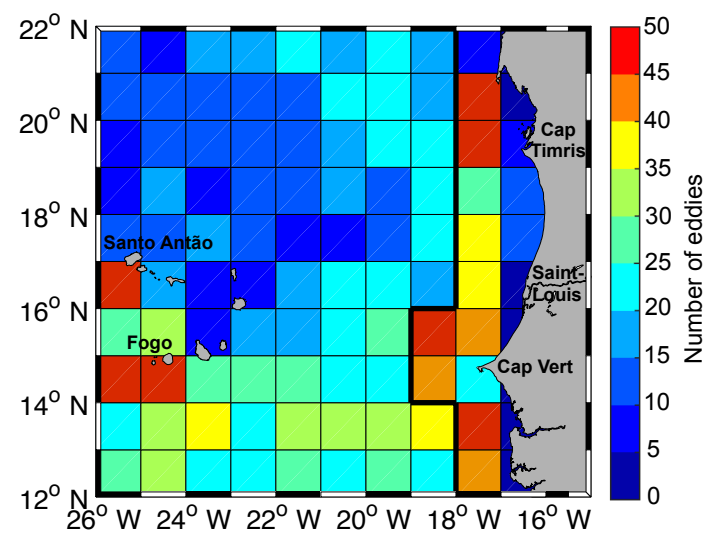

Figure 7. Number of eddies generated in $1^{\circ} \times 1^{\circ}$ boxes (colors) between 1995 and 2013 based on the results of the OW method. Marked are the headlands Cap Timris (Mauretania), Saint-Louis (Senegal), Cap-Vert (Senegal), and the islands Santo Antão (Cabo Verde) and Fogo (Cabo Verde), which can be associated with high eddy generation. The thick solid black line along $18^{\circ} \mathrm{W} / 19^{\circ} \mathrm{W}$ separates the coastal region from the offshore region.

(Sangrà et al., 2009). The propagation pathways can be separately investigated for the different eddy types: most of the anticyclones are generated along the coast south of Cap Timris, off Saint-Louis, and north off Cap-Vert. They propagate either north of $18^{\circ} \mathrm{N}$ from their generation areas westward into the open ocean or south of $18^{\circ} \mathrm{N}$ with a southward deflection offshore. Their mean westward propagation speed is $3.05 \pm 2.15 \mathrm{~km} \mathrm{~d}^{-1}$. Other generation hotspots for anticyclones are around the Cabo Verde islands south of Santo Antão and south of Fogo. For cyclones the generation areas are more concentrated than for anticyclones. North of Cap Timris and off Cap-Vert are the main hotspots near the coast. On their way westwards cyclones tend to have a northward deflection in their pathways. The hotspot for cyclone generation around the Cabo Verde islands is west of Fogo. Cyclones have a mean westward propagation speed of $2.9 \pm 2.15 \mathrm{~km} \mathrm{~d}^{-1}$. Although not significantly different, the larger westward propagation speed of anticyclones compared to cyclones does agree with theoretical considerations regarding the westward eddy drift on a beta plane (CushmanRoisin et al., 1990).

The main generation areas for ACMEs near the coast are north of Cap Timris and off Saint-Louis around $18^{\circ} \mathrm{N}$. ACMEs generated north of Cap Timris tend to have a slightly southward deflection on their way westwards into the open ocean, whereas the eddies generated off Saint-Louis show no meridional deflection and propagate along $\sim 18^{\circ} \mathrm{N}$ into the open ocean. Their mean westward propagation speed is $3.05 \pm 2.1 \mathrm{~km} \mathrm{~d}^{-1}$. The main generation area of ACMEs near Cabo Verde islands is located south of the northwesternmost island Santo Antão. 
(a)

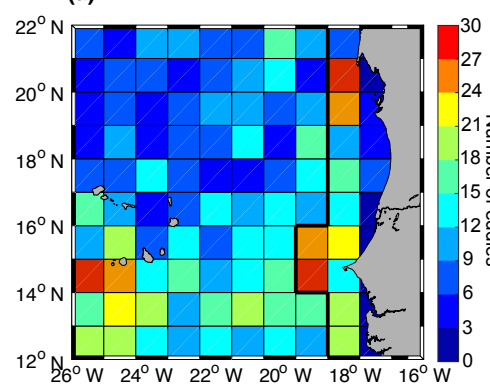

(c)

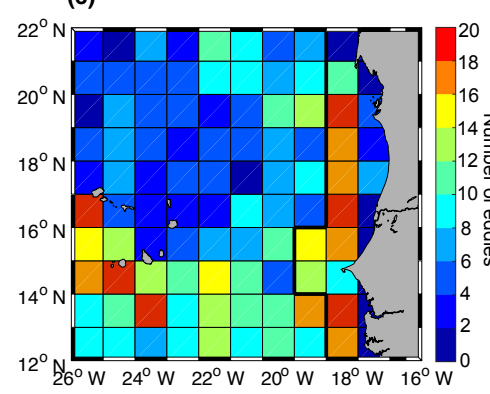

(b)

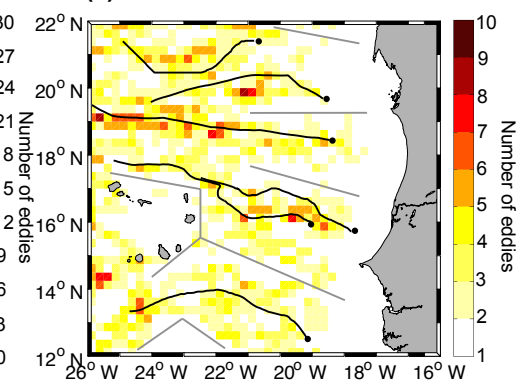

(d)

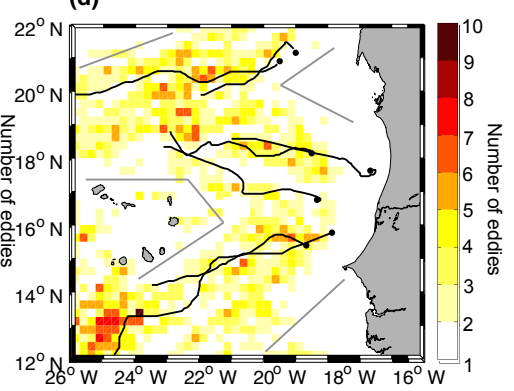

(e)

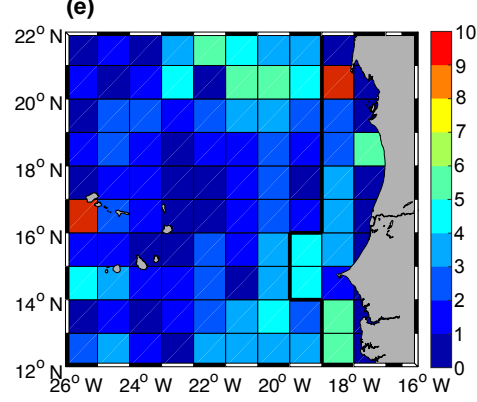

(f)

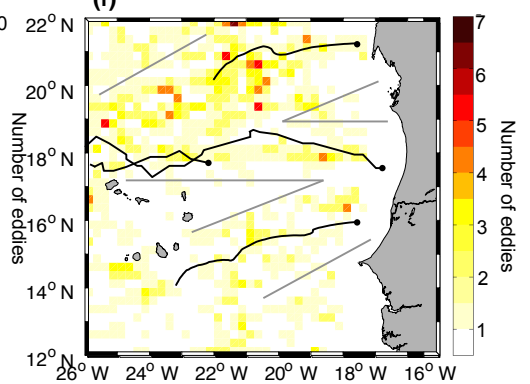

Figure 8. Number of eddies generated in $1^{\circ} \times 1^{\circ}$ boxes (a, c, e) and number of long-lived eddies detected in $1 / 6^{\circ} \times 1 / 6^{\circ}$ boxes based on the results of the OW method (b, d, f) for cyclones (a, b), anticyclones (c, d), and ACMEs (e, f). In (b), (d), and (f) only eddies with a lifetime larger than 35 days are counted. In (b), (d), and (f) main eddy propagation corridors are indicated by straight gray lines; black lines show trajectories of long-lived eddies with a lifetime larger than 150 days. The thick solid black line along $18^{\circ} \mathrm{W} / 19^{\circ} \mathrm{W}$ in (a), (c), and (e) separates the coastal region from the offshore region.

\subsection{Seasonal variability of eddy generation}

While the two eddy detection methods differ mostly in the number of identified eddies close to the coast, the season of peak eddy generation is very stable for both methods. A pronounced seasonality with a maximum of newly formed eddies during boreal summer (June/July) is obtained from both methods (Fig. 9). During April to June newly generated eddies are mostly cyclonic, while during October to December newly generated eddies are mostly anticyclonic (anticyclones plus ACMEs). These seasonal differences indicate different eddy generation mechanisms at play in the TANWA during the different seasons. Different mechanisms for the generation of eddies in eastern boundary upwelling regions have been proposed (e.g., Liang et al., 2012). Barotropic and baroclinic instabilities of the near-coastal currents (Pantoja et al., 2012) triggered by, e.g., the passage of poleward propagating coastal trapped waves (Zamudio et al., 2001, 2007), wind perturbations (Pares-Sierra et al., 1993), or interactions of the large-scale circulation with the bottom topography (Kurian et al., 2011) are the main processes identified for the eddy generation in eastern boundary upwelling regions. In the TANWA, the period of maximum eddy generation (June/July) is characterized by a strong near-surface boundary current, the MC (Lázaro et al., 2005) suggesting dynamic instabilities of the boundary current as an important generation mechanism. However, there is a difference in peak generation of cyclones and anticyclones. While the maximum generation of cyclones occurs in June during the acceleration phase of the MC, the seasonality of anticyclone generation is not as distinct with weaker maxima in July and at the end of the year. The generation of ACMEs has the main 

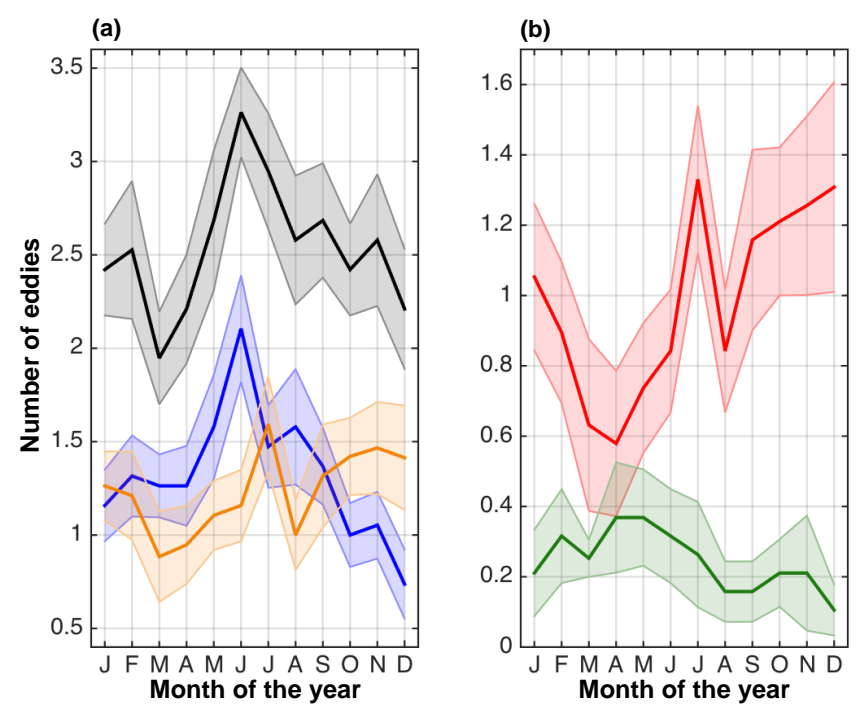

Figure 9. Seasonal cycle of the number of eddies generated in the costal region per year based on the results of the OW method as shown in Figs. 7 and 8. In (a) the seasonal cycle of all eddies is marked by the black line, of cyclones by the blue line and of all anticyclonic eddies by the orange line. In (b) the seasonal cycle of anticyclonic eddies is separated into anticyclones (red line) and ACMEs (green line). The shaded areas around the lines represent the standard error.

peak in April to May, which is at the end of the upwelling season. During that period the PUC is likely getting unstable and vanishes later on (Barton, 1989).

The seasonal peak in eddy occurrence appears to propagate westwards into the open ocean. To illustrate this, annual harmonics are fitted to the number of eddies detected per month in $2^{\circ} \times 2^{\circ}$ boxes (Fig. 10). Note, that the phase of a box is only shown when the amplitude is larger than 2.5 eddies per box. After the main generation of cyclones in the coastal area in June, the eddies enter the open ocean in late boreal autumn, passing the Cabo Verde islands and the ventilated gyre regime north of the CVFZ in boreal winter/spring. As mentioned before anticyclones are generated 1 to a few months later at the coast (July and October, November). They dominantly reach the open ocean in boreal winter and spring and accordingly pass the Cabo Verde islands and the ventilated gyre regime north of the CVFZ in late boreal spring and summer. Note, that the relatively clear signal of the annual harmonic of eddy detections (Fig. 10) also suggests that eddies with lifetime $>9$ months are more frequent in the TANWA than indicated by the statistical output of the algorithms.

\subsection{Mean eddy structure}

\subsubsection{Surface anomalies related to eddies}

For the three types of eddies, composite were constructed from daily SLA, SST, and SSS anomaly fields. An area of $300 \mathrm{~km} \times 300 \mathrm{~km}$ around every identified eddy center (center is the maximum value of SLA) was considered (Fig. 11). Overall we had about 40000 snapshots of eddies between 1993 and 2013 available to calculate the mean SLA and SST anomalies. To derive mean SSS anomalies, only about 10000 snapshots were merged because of the shorter time period of the SSS satellite data record (2010-2013).

For anticyclones, we found a positive SLA (maximum value in the eddy core is $6.9 \mathrm{~cm}(3.02 ; 11.01 \mathrm{~cm})$, given here as mean and the upper and lower limits of the $68 \%$ quartile range), a positive SST anomaly (maximum value in the eddy core $0.13^{\circ} \mathrm{C}\left(0.03 ; 0.24^{\circ} \mathrm{C}\right)$ ) and a positive SSS anomaly (maximum value in the eddy core is $0.20(-0.04$; $0.52)$ ). For cyclones, we found a negative SLA (minimum value in core $-5.5 \mathrm{~cm}(-1.57 ;-7.37 \mathrm{~cm})$ ), a negative SST anomaly (minimum value in the core is $-0.15^{\circ} \mathrm{C}(-0.04$; $-0.30^{\circ} \mathrm{C}$ )), and a negative SSS anomaly (minimum value in the core is $-0.16(0.08 ;-0.48))$. However, for the ACMEs (about $20 \%$ of the anticyclones) we found a negative SST anomaly (minimum value in the core is $-0.15^{\circ} \mathrm{C}(-0.04$; $\left.-0.31^{\circ} \mathrm{C}\right)$ ) was observed. The vertical structure of these anticyclones as obtained from temperature and salinity profiles revealed the characteristic pattern of ACMEs with a very shallow mode in the upper $100 \mathrm{~m}$ or so. ACMEs also have a negative SSS anomaly (minimum value in the core is -0.13 $(0.10 ;-0.33))$. For all eddy types, SST dominates sea surface density.

Compared to SLA and SST measurements, the satellitebased observations of SSS are afflicted with high uncertainties and large measuring gaps. However, in the composite it is possible to detect eddy-type dependent anomalies, even if they are not as clear and circular as the SLA and SST anomalies. The zonally stretched structures in the composites of SSS anomalies may also result from the coarser temporal resolution of SSS data (i.e., 10 days) resulting in a smearing of the eddy signal in the direction of propagation. Note, that the composites of SSS anomalies showed only coherent eddy structures when selecting energetic eddies (i.e., with a radius between 45 and $70 \mathrm{~km}$ and an absolute SLA anomaly $>2 \mathrm{~cm}$ ). The composites of SLA and SST anomalies are much less affected by the restriction with regard to the eddy amplitude.

In summary, the absolute SST and SSS anomalies of all three eddy types are of similar magnitude. The magnitude of absolute SLA of anticyclones and cyclones is also somehow similar, while ACMEs have a weaker SLA signature (which makes them more difficult to be detected and tracked by satellite altimetry). The maximum surface circumpolar velocity is $0.18 \pm 0.12$ in cyclones, $0.17 \pm 0.12$ in anticy- 
(a)

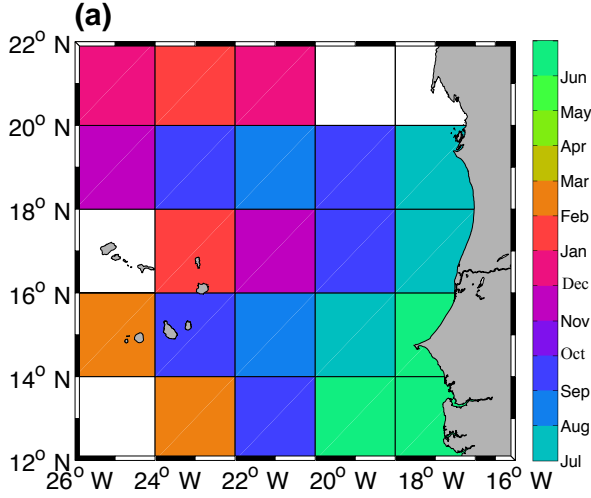

(b)

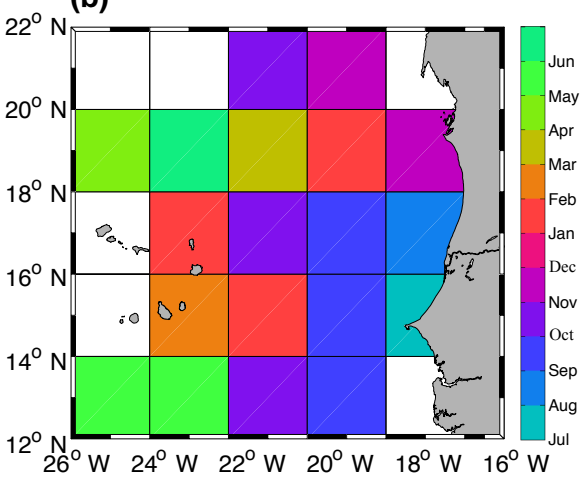

Figure 10. Phase of the annual harmonic of the number of detected eddies in $2^{\circ} \times 2^{\circ}$ boxes based on the results of the OW method for (a) cyclones and (b) anticyclones. Phases are only shown for boxes with an amplitude larger than 2.5 eddies. Phase is given in month of the year with maximum eddy number.
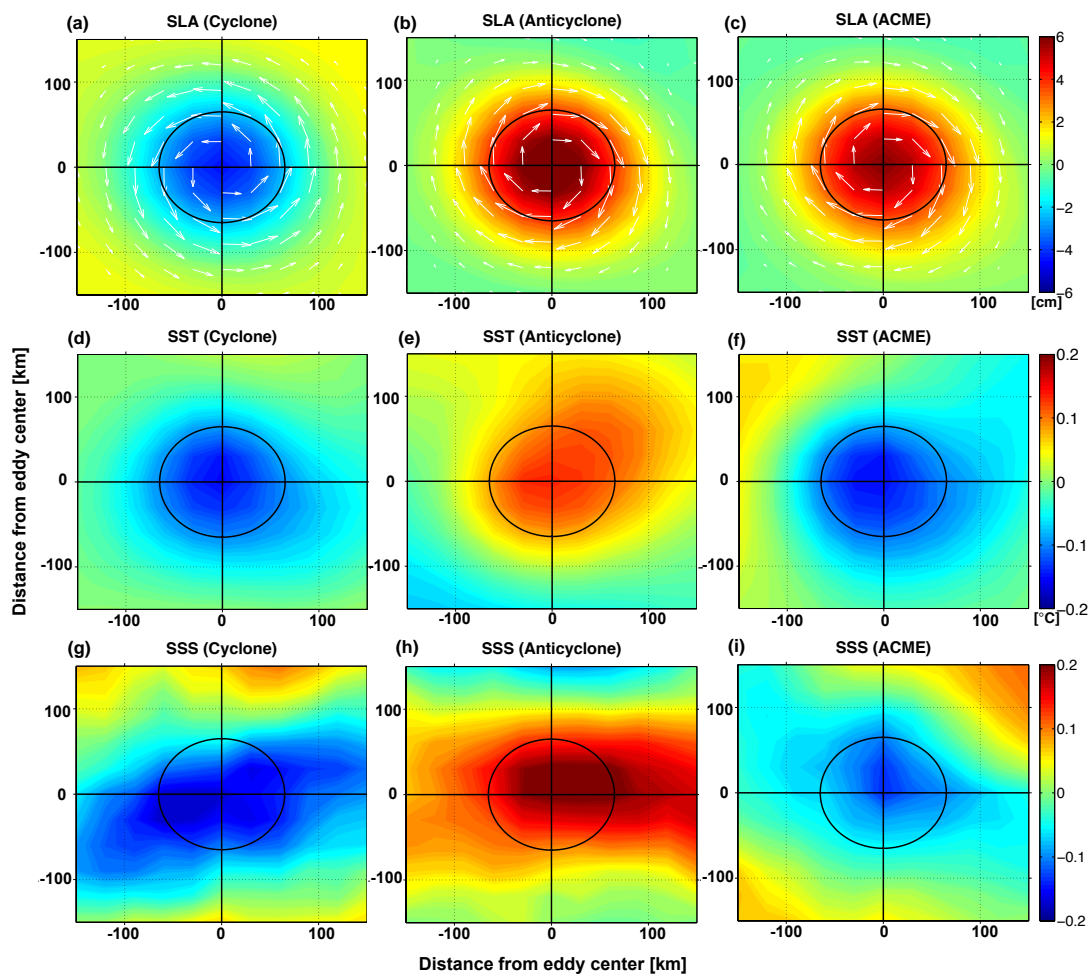

Figure 11. SLA, SST, and SSS anomalies of the composite cyclone, anticyclone, and ACME in the TANWA based on the results of the OW method. SLA (color) and the associated geostrophic velocity (white arrows) are shown for each eddy type in (a), (b), and (c); SST anomaly in (d), (e), and (f); and SSS anomaly in (g), (h), and (i). The circles mark the mean eddy radius.

clones, and $0.16 \pm 0.10 \mathrm{~m} \mathrm{~s}^{-1}$ in ACMEs. Overall, cyclones are slightly smaller, rotate faster, and therefore have a shorter lifetime than the other eddy types.

\subsubsection{Vertical structure of eddies}

Profiles from Argo floats, shipboard CTD, and moorings were used to derive a mean vertical eddy structure. Here, we calculated anomaly profiles of potential temperature, salinity and potential density derived from profiles inside and outside of eddies. The mean vertical structure and the anomalies presented here (Fig. 12) are based on 492 profiles in anticyclones, 411 profiles in cyclones, but only 95 profiles in ACMEs. Consequently, the statistics for ACMEs are weakest and the mean vertical structure must be interpreted with care. Cyclones, anticyclones, and ACMEs are characterized by a different shallowing/deepening of isopycnal surfaces. Anticyclones carry a warm and saline water anomaly, whereas 

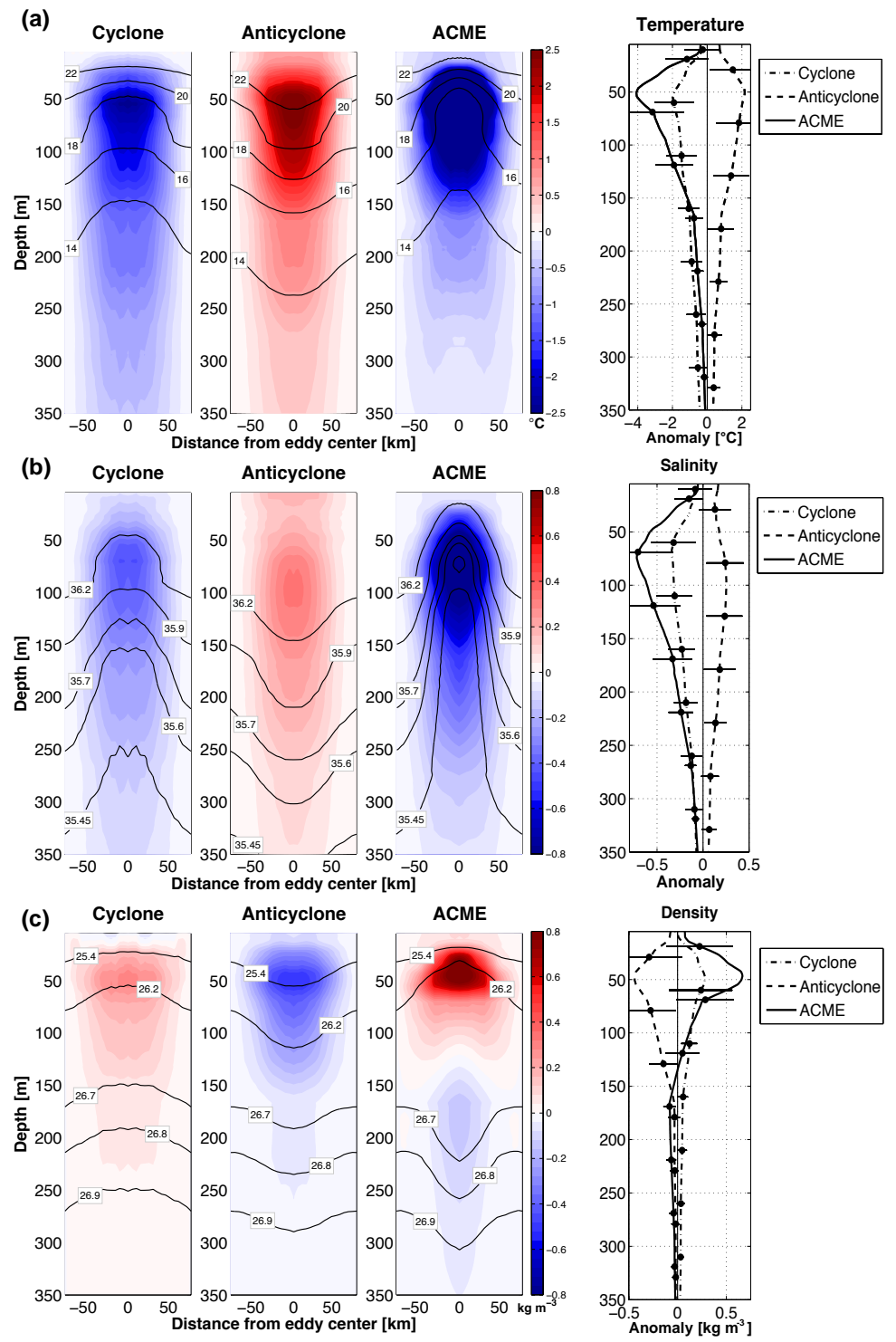

Figure 12. Vertical structure of the composite cyclone, anticyclone, and ACME in the TANWA as presented as sections through the eddy center (left three columns) and mean anomaly profiles (right column). In (a) potential temperature anomaly, in (b) salinity anomaly, and in (c) potential density anomaly as calculated by using the nearest profile outside of the eddy is shown. Black contour lines in the left three columns mark isolines of temperature (c), salinity (b), and potential density (c). In the right column, solid lines represent the composite ACME, dashed lines the anticyclone, and dashed-dotted lines the cyclone; the error bars at selected depths represent the standard deviation calculated from the individual anomaly profiles.

cyclones and ACMEs host cold and less saline water in their cores. The effect of temperature anomalies on density anomalies dominates over the effect of salinity anomalies, which results in a positive density anomaly associated with cyclones (shoaling of isopycnals) and a negative density anomaly associated with anticyclones (deepening of isopycnals). This is illustrated by the elevation (deepening) of $25 \mathrm{~m}$ $(36 \mathrm{~m})$ of the density surface of $26.2 \mathrm{~kg} \mathrm{~m}^{-3}$ in the core of the cyclone (anticyclone) compared to the surroundings. Due to the specific vertical structure of ACMEs, characterized by a strengthening of the anticyclonic rotation with depth in its upper part and a weakening of the anticyclonic rotation in its lower part, the ACMEs have a positive density anomaly in about the upper $100 \mathrm{~m}$ (shoaling of isopycnals) and a negative density anomaly below down to about $350 \mathrm{~m}$ (deepening of isopycnals). The mode water in the core of the ACMEs is only weakly stratified. This is illustrated by the elevation of $48 \mathrm{~m}$ of the density surface of $26.2 \mathrm{~kg} \mathrm{~m}^{-3}$ slightly above the core and the deepening of $52 \mathrm{~m}$ of the density surface of $26.7 \mathrm{~kg} \mathrm{~m}^{-3}$ below the core compared to the surroundings. From the mean vertical eddy profiles, we diagnose a maximum temperature anomaly underneath the mean 
mixed layer depth, which is at a depth of about $50 \mathrm{~m}$. It is $-2.42 \pm 1.23^{\circ} \mathrm{C}$ at $55 \mathrm{~m}$ for cyclones and $+1.88 \pm 1.37^{\circ} \mathrm{C}$ at $54 \mathrm{~m}$ for anticyclones. The maximum salinity anomaly is $-0.34 \pm 0.25$ at $70 \mathrm{~m}$ depth for cyclones and $+0.25 \pm 0.2$ at $100 \mathrm{~m}$ for anticyclones and as such located below the maximum temperature anomaly. The respective maximum density anomalies are, as expected, close to the location of the maximum temperature anomaly, and are $0.28 \pm 0.42 \mathrm{~kg} \mathrm{~m}^{-3}$ at $48 \mathrm{~m}$ for cyclones and $0.44 \pm \mathrm{kg} \mathrm{m}^{-3}$ at $50 \mathrm{~m}$ for anticyclones. The mean ACME structure is characterized by a much stronger temperature anomaly of $-4.0 \pm 2.2{ }^{\circ} \mathrm{C}$ at $51 \mathrm{~m}$ depth and salinity anomaly of $0.72 \pm 0.38$ at $74 \mathrm{~m}$ depth in comparison to cyclones and anticyclones. Note, that the cold and fresh SACW in the ACME core does not produce a positive temperature anomaly when it reaches deeper levels due to the downward bending of isopycnal surfaces below the eddy core. The ACME density anomaly has a maximum of $0.66 \pm 0.35 \mathrm{~kg} \mathrm{~m}^{-3}$ at about $47 \mathrm{~m}$ and a minimum of $-0.08 \pm 0.06 \mathrm{~kg} \mathrm{~m}^{-3}$ at about $168 \mathrm{~m}$, which reflects the shoaling and deepening of isopycnals towards the eddy center above and below its core. Note, that below the eddy core (> $150 \mathrm{~m}$ depth) horizontal density anomalies are dominated by salinity with temperature playing a minor role. For all eddy types, cyclones, anticyclones, and ACMEs, temperature, salinity, and density anomalies reach down to about 300-350 m depths with a maximum beneath the mixed layer or slightly deeper.

Chaigneau et al. (2011) observed mean maximum anomalies of $\pm 0.7^{\circ} \mathrm{C}$ in temperature and \pm 0.06 in salinity based on Argo float measurements in eddy cores within the southeastern Pacific. For the TANWA the mean maximum anomalies of about $\pm 2{ }^{\circ} \mathrm{C}$ in temperature and \pm 0.3 in salinity are more than twice as high. The presence of different water masses, cold and fresh SACW prevailing in the coastal region and warmer and saltier NACW further offshore, results in the large temperature and salinity anomalies in eddy cores in the TANWA compared to the southeastern Pacific. Furthermore the reference used for calculating an anomaly can create large differences. Chaigneau et al. (2011) computed the anomalies of Argo float profiles relative to interpolated climatological profiles taken from Commonwealth Scientific and Industrial Research Organization (CSIRO) Atlas of Regional Seas (CARS). Here, we tested five different references to calculate anomalies and found significantly different anomalies, even with reversed sign (Table 3 ). The differences in the mean anomalies depend on the reference profiles that are used. Besides the "next profile outside", we used different climatologies as reference. However, differences in temperature and salinity between the different climatologies are of similar magnitude as the derived mean anomalies of the different eddy types (Table 1). When using the "next profile outside" as reference, we obtained larger mean anomalies, which could suggest that the "next profile outside" is systematically biased by nearby eddies of reversed polarity (which are possibly not well identified by the eddy detect-
Table 3. Temperature and salinity anomalies of cyclones and anticyclones vertically averaged in the upper $350 \mathrm{~m}$. Anomaly profiles are calculated relative to different reference data sets: (1) the nearest in situ profile in time and space, (2) the CSIRO CARS2009a v1.1 climatology, (3) the monthly WOA09 climatology, (4) the monthly MIMOC v2.2 climatology, and (5) the monthly Levitus94 climatology (salt values are not included in monthly database).

\begin{tabular}{lrrrr}
\hline & \multicolumn{2}{c}{ Cyclones } & \multicolumn{2}{c}{ Anticyclones } \\
\cline { 2 - 5 } & $\begin{array}{r}\text { Temp } \\
\left({ }^{\circ} \mathrm{C}\right)\end{array}$ & Salt & $\begin{array}{r}\text { Temp } \\
\left({ }^{\circ} \mathrm{C}\right)\end{array}$ & Salt \\
\hline (1) Next profile outside & -1.22 & -0.26 & 0.87 & 0.13 \\
(2) CSIRO & -0.21 & -0.08 & 0.94 & 0.06 \\
(3) WOA & -0.32 & -0.10 & 0.85 & 0.05 \\
(4) MIMOC & -0.56 & -0.32 & 0.60 & -0.17 \\
(5) Levitus & -0.16 & & 0.97 & \\
\hline
\end{tabular}

ing methods). However, in particular in regions with strong gradients/fronts (e.g., CVFZ, coastal upwelling) with strong seasonality and variability, the "next profile outside" should deliver the most realistic background condition surrounding an eddy and thus should be preferably used to calculate water mass anomalies transported by eddies.

Here, we want to note that the uppermost data point (at $5 \mathrm{~m}$ ) of the mean temperature and salinity anomaly profiles of the three types of eddies from the selected in situ data (Fig. 12) agree well with the surface anomalies based on satellite data composites (Fig. 11) and amounts to maximum values of $-0.15^{\circ} \mathrm{C}$ (in situ: $-0.15^{\circ} \mathrm{C}$ ) for cyclones, $0.13^{\circ} \mathrm{C}$ (in situ: $0.25^{\circ} \mathrm{C}$ ) for anticyclones, and $-0.15^{\circ} \mathrm{C}$ (in situ: $-0.20^{\circ} \mathrm{C}$ ) for ACMEs; corresponding salinity anomalies are -0.16 (in situ: -0.10 ) for cyclones, 0.2 (in situ: 0.13 ) for anticyclones, and -0.13 (in situ: -0.11 ) for ACMEs.

\subsection{Contribution of eddies to zonal transport of properties}

\subsubsection{Thermohaline content and associated transport of eddies}

For all cyclones/anticyclones/ACMEs a mean eddy volume of $2.860 \times 10^{12} \mathrm{~m}^{3} / 3.089 \times 10^{12} \mathrm{~m}^{3} / 2.973 \times 10^{12} \mathrm{~m}^{3}$ is derived, considering their mean radii $(51 \mathrm{~km} / 53 \mathrm{~km} / 52 \mathrm{~km})$ and a mean depth of $350 \mathrm{~m}$ for all three eddy types. Distributed over a period of 1 year this leads to a westward volume flux associated with a single eddy of about $0.1 \mathrm{~Sv}$.

The mean three-dimensional structure of temperature and salinity anomalies associated with cyclones, anticyclones, and ACMEs (Fig. 12) was used to estimate profiles of AHA and ASA per meter (Fig. 13). The maximum AHA per meter is located at depths comparable to the maximum temperature anomaly and at about $55 \mathrm{~m}$ for all eddy types. The maximum ASA per meter is located deeper at about $80 \mathrm{~m}$ depth $(\sim 70 \mathrm{~m}$ depth for cyclones, $\sim 80 \mathrm{~m}$ for ACMEs, and 
(a)

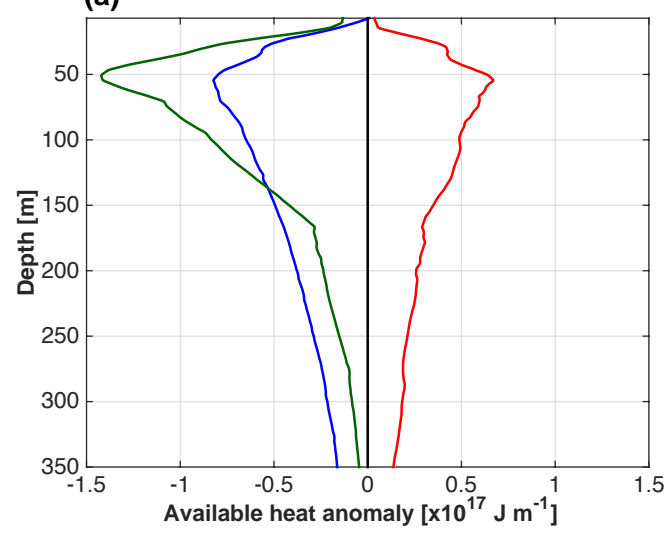

(b)

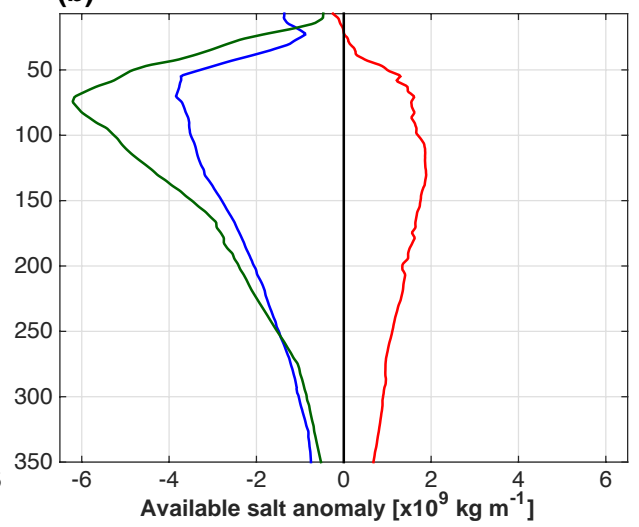

Figure 13. Mean profiles of available (a) heat and (b) salt anomaly per meter of the composite cyclone (blue line), anticyclone (red line), and ACME (green line).

Table 4. Total available heat anomaly $\left(\mathrm{AHA}_{\text {total }}\right)$ and total available salt anomaly $\left(\mathrm{ASA}_{\text {total }}\right)$ of the composite cyclones, anticyclones, and ACMEs as well as contribution of a single eddy to the annual heat and salt transport and its mean volume.

\begin{tabular}{lccc}
\hline & Cyclones & Anticyclones & ACMEs \\
\hline $\begin{array}{l}\text { AHA } \\
\left(\times 10^{18} \mathrm{~J}\right)\end{array}$ & -14.5 & 11.0 & -15.4 \\
\hline $\begin{array}{l}\mathrm{ASA}_{\text {total }} \\
\left(\times 10^{10} \mathrm{~kg}\right)\end{array}$ & -73.0 & 40.7 & -94.2 \\
\hline $\begin{array}{l}\text { Heat transport } \\
\left(\times 10^{11} \mathrm{~W}\right)\end{array}$ & -4.6 & 3.5 & -4.9 \\
\hline $\begin{array}{l}\text { Salt transport } \\
\left(\times 10^{3} \mathrm{~kg} \mathrm{~s}^{-1}\right)\end{array}$ & -23.2 & 12.9 & -29.9 \\
\hline $\begin{array}{l}\text { Volume } \\
\left(\times 10^{10} \mathrm{~m}^{3}\right)\end{array}$ & 286.0 & 308.9 & 297.3 \\
\hline
\end{tabular}

$\sim 110 \mathrm{~m}$ for anticyclones). The $\mathrm{AHA}_{\text {total }}\left(\mathrm{ASA}_{\text {total }}\right)$, derived by integrating the profiles of AHA (ASA) per meter from the surface to $350 \mathrm{~m}$, is $-14.5 \times 10^{18} \mathrm{~J}\left(-73.0 \times 10^{10} \mathrm{~kg}\right)$ for cyclones, $11.0 \times 10^{18} \mathrm{~J}\left(40.7 \times 10^{10} \mathrm{~kg}\right)$ for anticyclones, and $-15.4 \times 10^{18} \mathrm{~J}\left(-94.2 \times 10^{10} \mathrm{~kg}\right)$ for ACMEs (see also Table 4).

Comparing our results to the southeastern Pacific (cyclones: $\quad \mathrm{AHA}_{\text {total }}=-5.5 \times 10^{18} \mathrm{~J}, \quad \mathrm{ASA}_{\text {total }}=-9.8 \times$ $10^{10} \mathrm{~kg}$; anticyclones: $\mathrm{AHA}_{\text {total }}=8.7 \times 10^{18} \mathrm{~J}, \mathrm{ASA}_{\text {total }}=$ $23.8 \times 10^{10} \mathrm{~kg}$ ) (Chaigneau et al., 2011), we found an overall smaller volume of the eddies in the TANWA, but derived larger heat and salt anomalies. On the one hand, this could be explained by the fact that we averaged over a smaller area. However, regional differences should also exist, e.g., related to the boundary current hydrographic structure or the mean rotation speed (hence bending of isopycnals). For ACMEs in the southeastern Pacific there is only one recent estimate by Stramma et al. (2013) for comparison, who estimated the $\mathrm{AHA}_{\text {total }}$ and $\mathrm{ASA}_{\text {total }}$ of a well-observed ACME to be $17.7 \times 10^{18} \mathrm{~J}$ and $36.5 \times 10^{10} \mathrm{~kg}$, respectively. The heat and salt anomalies are on the same order as that found for the mean ACME in the TANWA but with reversed sign, which is remarkable. The ACME observed in the southeastern Pacific transports, in contrast to the composite ACMEs in the TANWA, warm and saline waters in its core offshore. One possible explanation is the different water mass characteristics in the source (coastal) region of the ACMEs in the southeastern Pacific compared to the TANWA.

Evenly distributed over a period of 1 year the heat (salt) transport associated with one single eddy is $-4.6 \times 10^{11} \mathrm{~W} \quad\left(-23.2 \times 10^{3} \mathrm{~kg} \mathrm{~s}^{-1}\right) \quad$ for cyclones, $3.5 \times 10^{11} \mathrm{~W}\left(12.9 \times 10^{3} \mathrm{~kg} \mathrm{~s}^{-1}\right)$ for anticyclones, and $-4.9 \times 10^{11} \mathrm{~W}\left(-29.9 \times 10^{3} \mathrm{~kg} \mathrm{~s}^{-1}\right)$ for ACMEs. As expected from the lower $\mathrm{AHA}_{\text {total }}\left(\mathrm{ASA}_{\text {total }}\right)$ that has been derived for eddies in the southeastern Pacific (Chaigneau et al., 2011), the heat (salt) transport due to eddies in the TANWA is comparably large (see also Table 4).

In order to estimate the large-scale impact of the heat and salt transport by these eddies in the TANWA, we define three characteristic areas (see Fig. 14): the extended boundary current region (area I), the transition zone (area II), and the subtropical gyre region (area III). Based on the results from the GEO method, 21 eddies are formed each year in the extended boundary current region of the TANWA. While about five eddies dissipate quickly and only influence the near-coastal regions, about 16 eddies per year leave the extended boundary current region and propagate into the transition zone of the TANWA (Fig. 14a). Based on the mean temperature and salinity anomalies derived above, it equates to a heat (salt) transport of $-35.9 \times 10^{11} \mathrm{~W}\left(-180.6 \times 10^{3} \mathrm{~kg} \mathrm{~s}^{-1}\right)$ by cyclones, $23.0 \times 10^{11} \mathrm{~W}\left(85.3 \times 10^{3} \mathrm{~kg} \mathrm{~s}^{-1}\right)$ by anticyclones, and $-8.8 \times 10^{11} \mathrm{~W}\left(-53.8 \times 10^{3} \mathrm{~kg} \mathrm{~s}^{-1}\right)$ by ACMEs. With regard to the number of eddies that dissolve in the different areas per year an equivalent surface heat flux (ESHF) is 
(a)

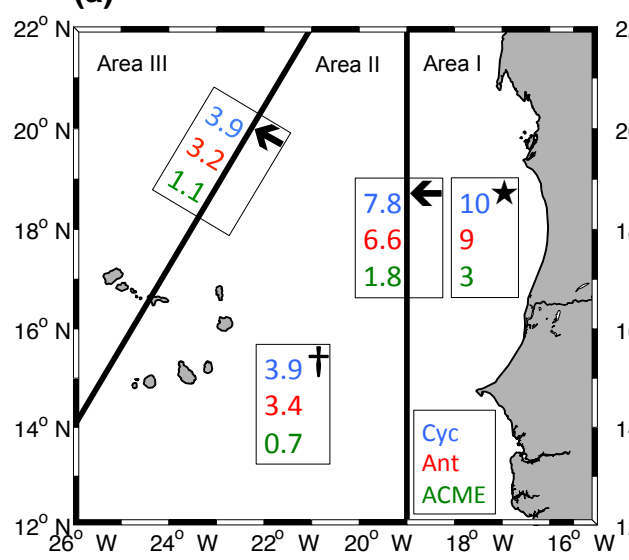

(b)

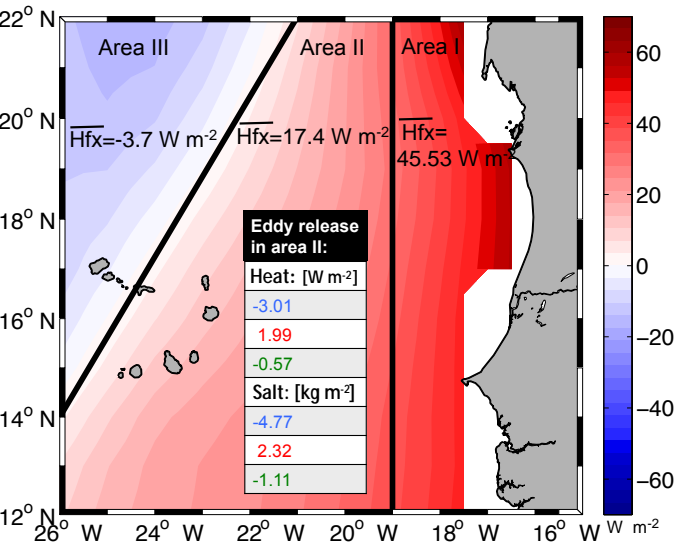

Figure 14. (a) Map of the TANWA divided into three areas (area I: the extended boundary current region, area II: the transition zone, and area III: the subtropical gyre region). Numbers inside of the boxes are the numbers of eddies (blue: cyclones, red: anticyclones, green: ACMEs), which are generated (star) and cease (cross) in an area or propagate from one area into another (arrow). (b) Annual mean net heat flux from NOC Surface Flux Dataset (colors) with three areas marked. Black numbers are the area-averaged net heat fluxes $(\overline{H f x})$ in the corresponding areas. The table includes the eddy-type dependent (blue: cyclones, red: anticyclones, green: ACMEs) heat and salt release in area II.

computed and compared with the annual mean net surface heat flux for the respective regions as taken from the NOC Surface Flux Dataset (Berry and Kent, 2011) (Fig. 14b).

The anomalies in heat and salt associated with the three different types of eddies partly counteract each other. Anomalies in cyclones and ACMEs are negative, indicating heat and salt deficiencies in their core, while anomalies in anticyclones represent a surplus of heat and salt with respect to the background conditions. The cyclonic eddies provide an ESHF in area II of about $-3.0 \mathrm{~W} \mathrm{~m}^{-2}$, anticyclones of about $+2.0 \mathrm{~W} \mathrm{~m}^{-2}$, and ACMEs of about $-0.6 \mathrm{~W} \mathrm{~m}^{-2}$, which results in a net ESHF associated with all eddies of about $-1.6 \mathrm{~W} \mathrm{~m}^{-2}$. This heat flux due to eddies represents about $10 \%$ of the net surface heat flux in the transition zone of the TANWA that is about $+17.4 \mathrm{~W} \mathrm{~m}^{-2}$.

In the open ocean of the TANWA, cyclones and ACMEs contribute to a cooling and freshening of the upper ocean and anticyclones to a warming and salinity increase. As such, the mesoscale eddy field and its seasonal to interannual variability can have an impact on the regional heat and salt budgets of the TANWA. However, because our calculations only account for long-lived eddies with a radius larger than $45 \mathrm{~km}$, the calculated absolute eddy fluxes represent a lower limit that might increase when accounting also for short-lived, non-coherent eddies and/or sub-mesoscale variability.

\subsubsection{Zonal eddy-dependent westward transport of SACW}

Many of the eddies that originate in the eastern boundary region carry water of South Atlantic origin westward. In order to quantify the SACW signature in the eddies, a water mass analysis was performed. For all isopycnals SACW (labeled
$100 \%$ ) and NACW (labeled $0 \%$ ) temperature and salinity pairs were defined using extremes of all observational data (see Fig. 2). Then the percentages of SACW concentrations contained inside the eddy cores were estimated. However, because the background field also transitions along the eddy trajectories towards stronger NACW characteristic, we estimated the SACW content of the eddies relative to the surrounding waters. Figure 15 shows the average vertical structure of the trapped SACW anomaly relative to the background for each eddy type. The different eddy types have a different potential in trapping SACW in their cores. Cyclones contain on average $16 \%$ (maximum core value: $35 \%$ ) more SACW than the surrounding water and ACMEs even $21 \%$ (maximum core value: $60 \%$ ). This implies a negative heat and salt anomaly along isopycnal layers inside of cyclones and ACMEs. Furthermore, it shows the prominent capability of ACMEs to trap and isolate anomalous water inside their cores. In contrast, the SACW anomaly in anticyclones is weak and negative (on average $-4 \%$; minimum core value $-10 \%$ ), implying that anticyclones contain on average a positive heat and salt anomaly along isopycnal layers. As such, anticyclones counteract the westward transport of SACW associated with the propagation of cyclones and ACMEs. Anticyclones instead transport small amounts of NACW westward.

To estimate an absolute transport of SACW from the eddy generation area at the eastern boundary into the open ocean, the mean percentages of SACW contained inside the different eddy types can be used. The highest percentage of SACW (> $80 \%)$ is found in the extended boundary current region (area I). Northwestward towards the open ocean, the SACW percentage decreases (area II 57\%, area III < 23\%; Fig. 16b). Hence, when the eddies are generated in the ex- 


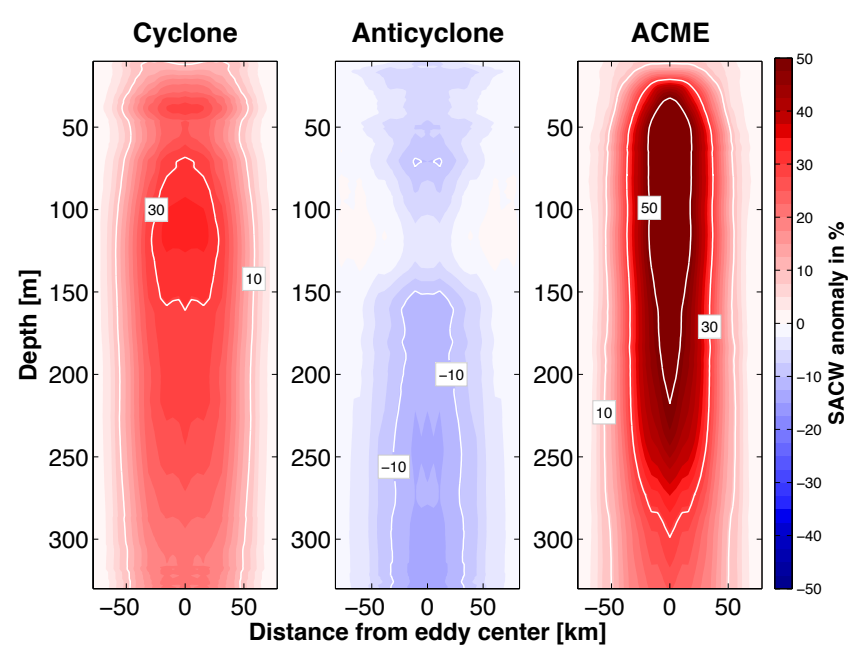

Figure 15. Vertical sections of SACW anomaly through the center of the composite cyclone (left), anticyclone (middle), and ACME (right) in the TANWA.

tended boundary current region (in area I) they trap waters with SACW signature in their cores and transport it westward into the open ocean (area II and area III), where waters with NACW signature prevail. These anomalous properties with respect to the surrounding waters can be visualized in a salinity versus sigma-theta diagram (Fig. 16a). ACMEs exhibit the strongest SACW signature, indicating again that ACMEs have the best capability to trap water. The percentage of SACW in the different eddy types within the three separated areas are shown in the white circles in Fig. 16b. Again the strong capability of ACMEs to transport SACW is obvious. In area II (background $\sim 57 \%$ SACW) ACMEs still exhibit $82 \%$ SACW and in area III (background $<23 \%$ $\mathrm{SACW}$ ) it is $78 \% \mathrm{SACW}$, indicating that ACMEs are only weakly affected by lateral and vertical mixing. Cyclones contain $69 \%$ SACW in area II and $52 \%$ SACW in area III and as such lose SACW signature from their cores much faster. Anticyclones with $59 \%$ SACW in area II and $29 \%$ SACW seem to have almost the same SACW signature as the background. This indicates that either they are not well isolated, and their cores are already replaced with the surrounding water, or that they are transporting low SACW signatures in their cores from the beginning.

Using the number of eddies passing the boundaries of the areas and the "excess" percentage of SACW in their cores (relative to the background), an "eddy-type dependent" absolute transport of SACW out of the boundary current was derived (Fig. 16b). We obtained an absolute transport of $2.07 \mathrm{~Sv}$ of SACW out of the boundary current near the coast into the extended boundary current region (area I) of which about $0.81 \mathrm{~Sv}$ of SACW reached the transition zone (area II). Further to the west, about $0.36 \mathrm{~Sv}$ of SACW reached the subtropical gyre region west of the Cabo Verde islands (area III). Considering the volume of the upper $350 \mathrm{~m}$ of the transition zone (area II; $2 \times 10^{5} \mathrm{~km}^{3}$ ) the eddy transport will replenish the SACW part in about 2.5 years. Note, that these calculations represent conservative assumptions about the SACW transport since the contribution of short-lived, non-coherent, and smaller-scale eddies to the SACW transport is not included. For example, the highly energetic cyclone generated at the headland of Cap-Vert discussed in detail by Alpers et al. (2013), which has a radius of 10 to $20 \mathrm{~km}$ and a Rossby number larger than 1 , is not detected by the eddy detection algorithms used in this paper due to its small scale, but certainly contributed to the westward transport of near-coastal water masses.

\section{Summary and conclusion}

Within this study we analyzed satellite-based remotely sensed data, including SLA, SST, SSS, as well as in situ temperature and salinity profiles, taken from Argo floats, ships, and moorings, in order to examine the eddy characteristics and dynamics in the TANWA. Eddies were identified based on their manifestation in SLA data using two different eddy detection algorithms, the OW method and the GEO method. Both detection algorithms produced rather similar results except for the open ocean/coastal transition zone, where the OW methods seem to overestimate the amount of eddies due to high vorticity values associated with the meandering boundary current.

We found that anticyclones (cyclones) are associated with enhanced (reduced) SLA, enhanced (reduced) SST and enhanced (reduced) SSS in their eddy cores. However, $20 \%$ of all eddies with enhanced SLA showed reduced SST and reduced SSS and we were able to classify these eddies as anticyclonic mode-water eddies (ACMEs). Of the average $146 \pm 4$ eddies detected per year in the TANWA over 19 years of SLA data, the ratio of cyclonic and anticyclonic eddies is nearly equal (52\% cyclones, $39 \%$ anticyclones, $9 \%$ ACMEs), with a similar radius of $56 \pm 12 \mathrm{~km}$ for all three eddy types.

In agreement with earlier findings (Chaigneau et al., 2009), we found eddies being generated mainly near the coast and here at some topographic "hot spots". For the TANWA these hot spots are associated with the headlands of Cap-Vert (Senegal) and Cap Timris (Mauretania). We could also confirm the existence of a seasonality in the eddy generation (Chaigneau et al., 2009; Kurczyn et al., 2012) and found cyclones form preferably during April to June, while anticyclones and ACMEs are mostly generated from October to December. After their generation, eddies of all three types propagate westward with a speed, $c$, of about $3.00 \pm 2.15 \mathrm{~km} \mathrm{~d}^{-1}$, which is in general agreement with the first baroclinic mode Rossby wave phase speed at that latitude range (Chelton et al., 1998). We found that anticyclones/cyclones follow distinct corridors with a meridional deflection towards the Equator/pole. This is in agreement 
(a)

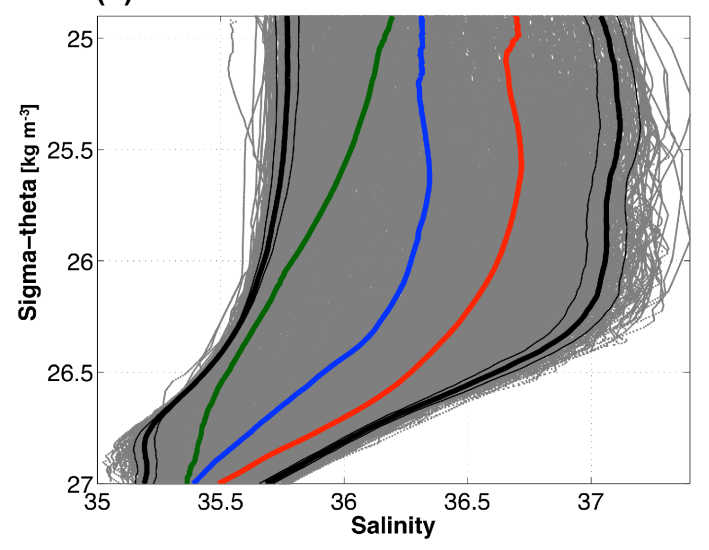

(b)

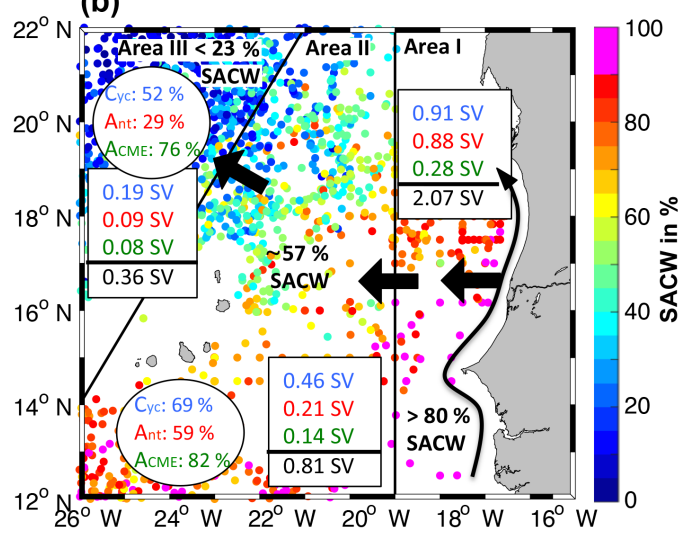

Figure 16. (a) $S-\sigma_{\theta}$ diagram with thick and thin black lines indicating mean and standard deviation, respectively, of characteristic SACW and NACW properties derived from the ensemble of profiles taken in the TANWA (gray lines). Mean eddy-dependent water mass properties are given for cyclones (blue line), anticyclones (red line), and ACMEs (green line). (b) Percentage of SACW in the upper $350 \mathrm{~m}$ as shown for all available profiles (color) and as mean numbers for the three regions: the extended boundary current region (area I), the transition zone (area II), and the subtropical gyre region (area III) that are separated by black straight lines. Numbers in the white circles are the mean percentage of SACW of the composite cyclones (blue), anticyclones (red), and ACMEs (green) in the corresponding areas. The eddy transport of SACW from the boundary current into area I, from area I into area II, and from area II into area III is marked by thick black arrows with transport numbers in Sv given in the white boxes for composite cyclones (blue), anticyclones (red), ACMEs (green), and total transport (black).

with the theoretical and observational findings of the deflection from the $\beta$-drift of anticyclones and cyclones (Chelton et al., 2011). In contrast, ACMEs do not show a significant meridional deflection.

We suspect that the eddy generation is related to instabilities of the eastern boundary current. Eddy generation resulting from interactions of coastal currents with headlands is a well-known process and has been extensively investigated (e.g., Røed, 1980; Klinger, 1994a, b; Pichevin and Nof, 1996; Crawford et al., 2002; Zamudio et al., 2007). Most likely the generation is driven by flow separation at the headlands of the West African coast, triggered by seasonality in the wind forcing. For the northeastern Pacific it has been shown that coastal trapped waves have an impact on the stability of coastal currents and hence eddy generation (Zamudio et al., 2001, 2006, 2007). Such eddy generation mechanisms may explain the high eddy generation in the TANWA found during phases of strongest boundary current velocities. However, the detailed investigation of the generation mechanisms of eddies in the TANWA requires realistic high-resolution modeling and is beyond the scope of the present study.

The maximum swirl velocity of the eddies, $U$, as obtained from the surface geostrophic velocity is about $14.7 \pm 9.5 \mathrm{~km} \mathrm{~d}^{-1}$ indicating a high nonlinearity of the observed eddies, i.e., $U / c>1$. Due to this nonlinearity the exchange between eddy core and surrounding water is limited and hence they are able to trap water masses and transport them over large distances. In the TANWA the eddies act as transport agents for SACW that is present in the eastern boundary upwelling region toward, and across the CVFZ into the subtropical gyre region, where NACW dominates.
In order to estimate the water mass anomalies transported by the different eddy types, their vertical water mass structures were estimated. Cyclones (anticyclones) are associated with maximum temperature/salinity anomalies of about $-2.42 \pm 1.23^{\circ} \mathrm{C} /-0.34 \pm 0.25\left(1.88 \pm 1.37^{\circ} \mathrm{C} / 0.25 \pm 0.2\right)$, respectively, most intense just beneath the mixed layer in the depth range 55 to $100 \mathrm{~m}$. With respect to water mass anomalies the ACMEs stand out because their maximum absolute anomaly is more than twice as large (temperature anomalies of $-4 \pm 2.2^{\circ} \mathrm{C}$ and salinity anomalies of $+0.72 \pm 0.38$ ) compared to the corresponding anomalies of cyclones or normal anticyclones. Moreover, their mixed layer depth is found at much shallower depth of 40 to $70 \mathrm{~m}$. Given the fundamentally different anomalies that are associated with the two types of eddies with anticyclonic surface flow (normal anticyclones and ACMEs), a separate treatment of these eddy types seems to be mandatory when discussing eddy transports. This has not been done routinely in the past (e.g., Chaigneau et al., 2009; Zhang et al., 2014) primarily because SLA data alone do not provide the necessary information. Here, we were able to distinguish ACMEs from normal anticyclones by using SSS and SST data in parallel.

The magnitude of the obtained anomalies varies according to the reference data set (background data) being used. We tested nearby in situ data collected outside of eddies as well as different climatological fields (Table 3) as, e.g., in Chaigneau et al. (2009). Using the inferred temperature and salinity anomalies, we were able to calculate the associated heat (salt) transports for the different eddy types. They amount to $-4.6 \times 10^{11} \mathrm{~W}\left(-23.15 \times 10^{3} \mathrm{~kg} \mathrm{~s}^{-1}\right)$ for cyclones, $3.5 \times 10^{11} \mathrm{~W}\left(12.9 \times 10^{3} \mathrm{~kg} \mathrm{~s}^{-1}\right)$ for anticyclones, 
and $-4.9 \times 10^{11} \mathrm{~W}\left(-29.9 \times 10^{3} \mathrm{~kg} \mathrm{~s}^{-1}\right)$ for ACMEs. Out of the 21 eddies formed each year in the TANWA along the eastern boundary, five dissipate in a band of about $250 \mathrm{~km}$ width near the coast and about 16 propagate into the open ocean adding up to an annual eddy net heat (salt) transport of about $50 \times 10^{11} \mathrm{~W}\left(-150 \times 10^{3} \mathrm{~kg} \mathrm{~s}^{-1}\right)$. Converting the divergence of the heat transport in the transition zone (area II) into an equivalent surface heat flux we found a cooling of the ocean of $-1.6 \mathrm{~W} \mathrm{~m}^{-2}$ due to eddy heat transport, which as such balances about $10 \%$ of the net surface heat flux of $17.4 \mathrm{~W} \mathrm{~m}^{-2}$ as obtained from the NOC Surface Flux Dataset (Berry and Kent, 2011).

The TANWA is a crossroad for water masses, with NACW prevailing in the northwest within the ventilated subtropical gyre and SACW in the eastern boundary upwelling region. In order to estimate the dispersal of SACW due to eddies within the TANWA, we analyzed the SACW content in the three different eddy types using the in situ profile data. We found that cyclones contain on average about $16 \%$ more SACW than the surrounding water, ACMEs $21 \%$, and normal anticyclones do not carry any SACW anomaly. Some ACMEs efficiently isolate their eddy cores from the surrounding waters reaching maximum SACW anomalies of more than $60 \%$, which indicates a high nonlinearity and coherence of these eddies (Karstensen et al., 2015).

Considering the total tracer transport of the eddies along isopycnals (spiciness), the negative heat and salt anomaly within cyclones and ACMEs results in a mean water mass transport of $2.07 \mathrm{~Sv}$ of SACW out of the boundary current region, of which about $0.36 \mathrm{~Sv}$ of SACW reach the subtropical gyre region northwest of the Cabo Verde islands. Hence, the SACW transport due to eddies would renew the SACW part of the transition zone located between the extended eastern boundary region and the subtropical gyre region (assuming a layer thickness of $350 \mathrm{~m}$ ) in about 2.5 years.

This study gives a first insight into the types and characteristics of eddies within the TANWA as well as in the fluxes of heat and salt associated with their westward propagation. Remaining open questions regard the importance of short-lived eddies for the transport of heat and salt (which could not be evaluated due to the resolution of the available data sets), as well as the individual processes responsible for eddy generation. The distinction of anticyclonic rotating eddies into ACMEs and "normal anticyclones" seems to be mandatory for future eddy studies as these two eddy types strongly differ in their efficiency to carry water mass anomalies. Moreover, the biogeochemical responses in ACMEs have been found to be very distinct from normal anticyclones and a sufficient representation of both types of anticyclones in coupled physical-biogeochemical models may be crucial for a realistic simulation of eastern boundary upwelling systems.

\section{Data availability}

The used satellite data SLA, SST and SSS can be downloaded at http://www.aviso.altimetry.fr/en/data/products/ sea-surface-height-products/global/msla-h.html, http: //www.remss.com/measurements/sea-surface-temperature/ oisst-description and http://catds.ifremer.fr/Products/ Available-products-from-CEC-OS/Locean-v2013, respectively. The NOCS Surface Flux is accessible at http://noc.ac.uk/science-technology/earth-ocean-system/ atmosphere-ocean/noc-surface-flux-dataset. The Argo float data is freely available at http://www.argodatamgt.org/ Access-to-data/Argo-data-selection, the exact same dataset used in the paper is downloaded in January 2015 and available at http://dx.doi.org/10.13155/29825. The assembled shipboard measurements (20 research cruises) and the part of the CVOO mooring data used in this paper are available at https://doi.pangaea.de/10.1594/PANGAEA.860251.

Acknowledgements. This study is funded by the Deutsche Bundesministerium für Bildung und Forschung (BMBF) as part of the project AWA (01DG12073E) and by the Deutsche Forschungsgemeinschaft as part of the Sonderforschungsbereich 754 "Climate - Biogeochemistry Interactions in the Tropical Oceans" and the project FOR1740 and through several research cruises with RV Meteor, RV Maria S. Merian, RV Poseidon, and RV L'Atalante. We thank the captains and crew as well as all chief scientists and scientists of the involved research vessels and our technical group for their help with the fieldwork. Furthermore, the authors thank Ping Chang, Rebecca Hummels, Tim Fischer, and Robert Kopte for helpful discussions. For ship and mooring data processing we thank Gerd Krahmann. In addition we thank the international Argo program and the national programs that contribute to it, which collected the data and made it freely available. The Argo program is part of the Global Ocean Observing System. The altimeter products were produced and distributed by AVISO (http://www.aviso.altimetry.fr/), as part of the Ssalto ground-processing segment. The Microwave OI SST data are produced by Remote Sensing Systems and sponsored by National Oceanographic Partnership Program (NOPP), the NASA Earth Science Physical Oceanography Program, and the NASA MEaSUREs DISCOVER Project. The LOCEAN_v2013 Sea Surface Salinity maps have been produced by LOCEAN/IPSL (UMR CNRS/UPMC/IRD/MNHN) laboratory that participates to the Ocean Salinity Expertise Center (CECOS) of Centre Aval de Traitemenent des Donnees SMOS (CATDS). This product is distributed by the Ocean Salinity Expertise Center (CECOS) of the CNES-IFREMER Centre Aval de Traitemenent des Donnees SMOS (CATDS), at IFREMER, Plouzane (France). The NOCS Surface Flux Dataset v2.0 is distributed from the US National Center for Atmospheric Research (NCAR) and the British Atmospheric Data Centre (BADC). The observations used to construct the NOC Surface Flux Dataset come from the International Comprehensive Ocean-Atmosphere Data Set (ICOADS).

Edited by: M. Hecht 


\section{References}

Alpers, W., Brandt, P., Lazar, A., Dagorne, D., Sow, B., Faye, S., Hansen, M. W., Rubino, A., Poulain, P.-M., and Brehmer, P.: A small-scale oceanic eddy off the coast of West Africa studied by multi-sensor satellite and surface drifter data, Remote Sens. Environ., 129, 132-143, 2013.

ARGO: Argo float data, http://www.argodatamgt.org/ Access-to-data/Argo-data-selection, 2015.

AVISO: MSLA - $\mathrm{H}$ : Maps of Sea Level Anomalies: Height, http://www.aviso.altimetry.fr/en/data/products/ sea-surface-height-products/global/msla-h.html, 2015.

Barton, E.: Meanders, eddies and intrusions in the thermohaline front off Northwest Africa, Oceanol. Acta, 10, 267-283, 1987.

Barton, E. D.: The Poleward Undercurrent on the Eastern Boundary of the Subtropical North Atlantic, in: Poleward Flows Along Eastern Ocean Boundaries, edited by: Neshyba, S. J., Mooers, C. N. K., Smith, R. L., and Barber, R. T., Coastal and Estuarine Studies, Springer New York, 82-95, 1989.

Berry, D. I. and Kent, E. C.: Air-Sea fluxes from ICOADS: the construction of a new gridded dataset with uncertainty estimates, Int. J. Climatol., 31, 987-1001, 2011.

Boutin, J., Martin, N., Reverdin, G., Yin, X., and Gaillard, F.: Sea surface freshening inferred from SMOS and ARGO salinity: impact of rain, Ocean Sci., 9, 183-192, doi:10.5194/os-9-183-2013, 2013.

Brandt, P., Bange, H. W., Banyte, D., Dengler, M., Didwischus, S.-H., Fischer, T., Greatbatch, R. J., Hahn, J., Kanzow, T., Karstensen, J., Körtzinger, A., Krahmann, G., Schmidtko, S., Stramma, L., Tanhua, T., and Visbeck, M.: On the role of circulation and mixing in the ventilation of oxygen minimum zones with a focus on the eastern tropical North Atlantic, Biogeosciences, 12, 489-512, doi:10.5194/bg-12-489-2015, 2015.

Carval, T., Keeley, R., Takatsuki, Y., Yoshida, T., Schmid, C., Goldsmith, R., Wong, A., Thresher, A., Tran, A., Loch, S., and Mccreadie, R.: Argo user's manual V3.2, doi:10.13155/29825, 2015.

CATDS: French ground segment for the SMOS Level 3 and 4 data, http://catds.ifremer.fr/Products/ Available-products-from-CEC-OS/Locean-v2013, 2015.

Chaigneau, A., Gizolme, A., and Grados, C.: Mesoscale eddies off Peru in altimeter records: Identification algorithms and eddy spatio-temporal patterns, Prog. Oceanogr., 79, 106-119, 2008.

Chaigneau, A., Eldin, G., and Dewitte, B.: Eddy activity in the four major upwelling systems from satellite altimetry (1992-2007), Prog. Oceanogr., 83, 117-123, 2009.

Chaigneau, A., Le Texier, M., Eldin, G., Grados, C., and Pizarro, O.: Vertical structure of mesoscale eddies in the eastern South Pacific Ocean: A composite analysis from altimetry and Argo profiling floats, J. Geophys. Res.-Ocean., 116, C11025, doi:10.1029/2011JC007134, 2011.

Chang, C.-H., Xie, S.-P., Schneider, N., Qiu, B., Small, J., Zhuang, W., Taguchi, B., Sasaki, H., and Lin, X.: East Pacific ocean eddies and their relationship to subseasonal variability in Central American wind jets, J. Geophys. Res.-Ocean., 117, C10001, doi:10.1029/2011JC007315, 2012.

Chelton, D. B., deSzoeke, R. A., Schlax, M. G., El Naggar, K., and Siwertz, N.: Geographical Variability of the First Baroclinic Rossby Radius of Deformation, J. Phys. Oceanogr., 28, 433-460, 1998.
Chelton, D. B., Schlax, M. G., Samelson, R. M., and de Szoeke, R. A.: Global observations of large oceanic eddies, Geophys. Res. Lett., 34, L15606, doi:10.1029/2007GL030812, 2007.

Chelton, D. B., Schlax, M. G., and Samelson, R. M.: Global observations of nonlinear mesoscale eddies, Prog. Oceanogr., 91, 167-216, 2011.

Crawford, W., Cherniawsky, J., Foreman, M., and Gower, J.: Formation of the Haida - 1998 oceanic eddy, J. Geophys. Res.-Ocean., 107, 6-1-6-11, 2002.

Cushman Roisin, B. and Tang, B.: Geostrophic Turbulence and Emergence of Eddies beyond the Radius of Deformation, J. Phys. Oceanogr., 20, 97-113, 1990

Cushman-Roisin, B., Tang, B., and Chassignet, E. P.: Westward Motion of Mesoscale Eddies, J. Phys. Oceanogr., 20, 758-768, 1990.

de Boyer Montégut, C., Madec, G., Fischer, A. S., Lazar, A., and Iudicone, D.: Mixed layer depth over the global ocean: An examination of profile data and a profile-based climatology, J. Geophys. Res.-Ocean., 109, C12003, doi:10.1029/2004JC002378, 2004.

Fu, L.-L. and Ferrari, R.: Observing Oceanic Submesoscale Processes From Space, Eos, T. Am. Geophys. Union, 89, 488-488, 2008.

Garzoli, S. L. and Katz, E. J.: The Forced Annual Reversal of the Atlantic North Equatorial Countercurrent, J. Phys. Oceanogr., 13, 2082-2090, 1983.

Glessmer, M. S., Eden, C., and Oschlies, A.: Contribution of oxygen minimum zone waters to the coastal upwelling off Mauritania, Prog. Oceanogr., 83, 143-150, 2009.

Hagen, E.: A meandering intermediate front North-West off Cape Verde islands, 1985, Oceanogr. Trop., 20, 71-83, 1985.

Hood, E. M. C., Sabine, L., and Sloyan, B. M.: The GO-SHIP repeat hydrography manual: A collection of expert reports and guidelines, IOCCP Rep. 14, 2010.

Hughes, P. and Barton, E. D.: Stratification and water mass structure in the upwelling area off Northwest Africa in April/May 1969 , Deep-Sea Res., 21, 6111-628, 1974

Isern-Fontanet, J., García-Ladona, E., and Font, J.: Vortices of the Mediterranean Sea: An Altimetric Perspective, J. Phys. Oceanogr., 36, 87-103, 2006.

Johns, W. E., Zantopp, R. J., and Goni, G. J.: Cross-gyre transport by North Brazil Current rings, Elsev. Oceanogr. Serie., 68, 411441, 2003.

Jones, P. G. W. and Folkard, A. R.: Chemical oceanographical observations off the coast of North-West Africa, with special reference to the process of upwelling, Rapports et proc's verbaux du Conseil International pour l'Exploration de la Mer, 159, 38-60, 1970

Karstensen, J., Fiedler, B., Schütte, F., Brandt, P., Körtzinger, A., Fischer, G., Zantopp, R., Hahn, J., Visbeck, M., and Wallace, D.: Open ocean dead zones in the tropical North Atlantic Ocean, Biogeosciences, 12, 2597-2605, doi:10.5194/bg-12-2597-2015, 2015.

Klinger, B. A.: Baroclinic eddy generation at a sharp corner in a rotating system, J. Geophys. Res.-Ocean., 99, 12515-12531, 1994a.

Klinger, B. A.: Inviscid Current Separation from Rounded Capes, J. Phys. Oceanogr., 24, 1805-1811, 1994b.

Kostianoy, A. G. and Belkin, I. M.: A Survey of Observations on Emtrathermocline Eddies in the World Ocean, in: Elsev. 
Oceanogr. Serie., edited by: Nihoul, J. C. J. and Jamart, B. M., Elsevier, 1989.

Kurczyn, J., Beier, E., Lavín, M., and Chaigneau, A.: Mesoscale eddies in the northeastern Pacific tropical - subbtropical transition zone: Statistical characterization from satellite altimetry, J. Geophys. Res.-Ocean., 117, C10021, doi:10.1029/2012JC007970, 2012.

Kurian, J., Colas, F., Capet, X., McWilliams, J. C., and Chelton, D. B.: Eddy properties in the California current system, J. Geophys. Res.-Ocean., 116, C08027, doi:10.1029/2010JC006895, 2011.

Lázaro, C., Fernandes, M. J., Santos, A. M. P., and Oliveira, P.: Seasonal and interannual variability of surface circulation in the Cape Verde region from 8 years of merged T/P and ERS-2 altimeter data, Remote Sens. Environ., 98, 45-62, 2005.

Liang, J.-H., McWilliams, J. C., Kurian, J., Colas, F., Wang, P., and Uchiyama, Y.: Mesoscale variability in the northeastern tropical Pacific: Forcing mechanisms and eddy properties, J. Geophys. Res.-Ocean., 117, C07003, doi:10.1029/2012JC008008, 2012.

Liu, Y., Dong, C., Guan, Y., Chen, D., McWilliams, J., and Nencioli, F.: Eddy analysis in the subtropical zonal band of the North Pacific Ocean, Deep-Sea Res. Pt. I, 68, 54-67, 2012.

Luyten, J. R., Pedlosky, J., and Stommel, H.: The ventilated thermocline, J. Phys. Oceanogr., 13, 292-309, 1983.

Mittelstaedt, E.: The upwelling area off Northwest Africa - a description of phenomena related to coastal upwelling, Prog. Oceanogr., 12, 307-331, 1983.

Mittelstaedt, E.: The ocean boundary along the Northwest African Coast - circulation and oceanographic properties at the seasurface, Prog. Oceanogr., 26, 307-355, 1991.

Nencioli, F., Dong, C., Dickey, T., Washburn, L., and McWilliams, J. C.: A Vector Geometry-Based Eddy Detection Algorithm and Its Application to a High-Resolution Numerical Model Product and High-Frequency Radar Surface Velocities in the Southern California Bight, J. Atmos. Ocean. Tech., 27, 564-579, 2010.

NOC: NOC Surface Flux Dataset, http://noc.ac.uk/ science-technology/earth-ocean-system/atmosphere-ocean/ noc-surface-flux-dataset, 2015.

Okubo, A.: Horizontal dispersion of floatable particles in the vicinity of velocity singularities such as convergences, Deep-Sea Res. Oceanogr., 17, 445-454, 1970.

Ould-Dedah, S., Wiseman Jr, W. J., and Shaw, R. F.: Spatial and temporal trends of sea surface temperature in the northwest African region, Oceanol. Acta, 22, 265-279, 1999.

PANGEA: Occurrence and characteristics of mesoscale eddies in the tropical northeast Atlantic Ocean, doi:10.1594/PANGAEA.860251, 2013.

Pantoja, D., Marinone, S., Parés-Sierra, A., and Gómez-Valdivia, F.: Numerical modeling of seasonal and mesoscale hydrography and circulation in the Mexican Central Pacific Modelación numérica de la hidrografía y circulación estacional y de mesoescala en el Pacífico central mexicano, Cienc. Mar., 38, 363-379, 2012.

Pares-Sierra, A., White, W. B., and Tai, C. K.: Wind-driven Coastal Generation of Annual Mesoscale Eddy Activity in the California Current, J. Phys. Oceanogr., 23, 1110-1121, 1993.

Pastor, M. V., Pelegrí, J. L., Hernández-Guerra, A., Font, J., Salat, J., and Emelianov, M.: Water and nutrient fluxes off Northwest Africa, Cont. Shelf Res., 28, 915-936, 2008.
Pegliasco, C., Chaigneau, A., and Morrow, R.: Main eddy vertical structures observed in the four major Eastern Boundary Upwelling Systems, J. Geophys. Res., 120, 6008-6033, 2015

Peña-Izquierdo, J., Pelegrí, J. L., Pastor, M. V., Castellanos, P., Emelianov, M., Gasser, M., Salvador, J., and VázquezDomínguez, E.: The continental slope current system between Cape Verde and the Canary Islands, Sci. Mar., 76, 65-78, 2012.

Peña-Izquierdo, J., van Sebille, E., Pelegrí, J. L., Sprintall, J., Mason, E., Llanillo, P. J., and Machín, F.: Water mass pathways to the North Atlantic oxygen minimum zone, J. Geophys. Res.Ocean., 120, 3350-3372, 2015.

Pichevin, T. and Nof, D.: The eddy cannon, Deep-Sea Res. Pt. I, 43, 1475-1507, 1996.

Polonsky, A. and Artamonov, Y.: North equatorial countercurrent in the tropical Atlantic: Multi-jet structure and seasonal variability, Deutsche Hydrographische Zeitschrift, 49, 477-495, 1997.

REMSS: Microwave OI SST Product Description, http: //www.remss.com/measurements/sea-surface-temperature/ oisst-description, 2015.

Richardson, P. L. and Reverdin, G.: Seasonal cycle of velocity in the Atlantic North Equatorial Countercurrent as measured by surface drifters, current meters, and ship drifts, J. Geophys. Res.-Ocean., 92, 3691-3708, 1987.

Røed, L. P.: Curvature effects on hydraulically driven inertial boundary currents, J. Fluid Mech., 96, 395-412, 1980.

Sangrà, P., Pascual, A., Rodríguez-Santana, Á., Machín, F., Mason, E., McWilliams, J. C., Pelegrí, J. L., Dong, C., Rubio, A., Arístegui, J., Marrero-Díaz, Á., Hernández-Guerra, A., Martínez-Marrero, A., and Auladell, M.: The Canary Eddy Corridor: A major pathway for long-lived eddies in the subtropical North Atlantic, Deep-Sea Res. Pt. I, 56, 2100-2114, 2009.

Schmidtko, S., Johnson, G. C., and Lyman, J. M.: MIMOC: A global monthly isopycnal upper-ocean climatology with mixed layers, J. Geophys. Res.-Ocean., 118, 1658-1672, 2013.

Siedler, G., Zangenberg, N., Onken, R., and Morlière, A.: Seasonal changes in the tropical Atlantic circulation: Observation and simulation of the Guinea Dome, J. Geophys. Res.-Ocean., 97, 703$715,1992$.

Stramma, L. and Isemer, H.-J.: Seasonal variability of meridional temperature fluxes in the eastern North Atlantic Ocean, J. Mar. Res., 46, 281-299, 1988.

Stramma, L. and Siedler, G.: Seasonal changes in the North Atlantic subtropical gyre, J. Geophys. Res.-Ocean., 93, 8111-8118, 1988

Stramma, L. and Schott, F.: The mean flow field of the tropical Atlantic Ocean, Deep-Sea Res. Pt. II, 46, 279-303, 1999.

Stramma, L., Bange, H. W., Czeschel, R., Lorenzo, A., and Frank, M.: On the role of mesoscale eddies for the biological productivity and biogeochemistry in the eastern tropical Pacific Ocean off Peru, Biogeosciences, 10, 7293-7306, doi:10.5194/bg-10-72932013, 2013.

Wooster, W. S., Bakun, A., and McLain, D. R.: Seasonal upwelling cycle along the eastern boundary of the North Atlantic, J. Mar. Res., 34, 131-141, 1976

Weiss, J.: The dynamics of enstrophy transfer in two-dimensional hydrodynamics, Physica D, 48, 273-294, 1991.

Yin, X., Boutin, J., and Spurgeon, P.: First assessment of SMOS data over open ocean: Part I - Pacific Ocean, IEEE T. Geosci. Remote, 50, 1648-1661, 2012. 
Zamudio, L., Leonardi, A. P., Meyers, S. D., and O'Brien, J. J.: ENSO and eddies on the southwest coast of Mexico, Geophys. Res. Lett., 28, 13-16, 2001.

Zamudio, L., Hurlburt, H. E., Metzger, E. J., Morey, S. L., O’Brien, J. J., Tilburg, C., and Zavala-Hidalgo, J.: Interannual variability of Tehuantepec eddies, J. Geophys. Res.-Ocean., 111, C05001, doi:10.1029/2005JC003182, 2006.
Zamudio, L., Hurlburt, H. E., Metzger, E. J., and Tilburg, C. E.: Tropical wave - induced oceanic eddies at Cabo Corrientes and the María Islands, Mexico, J. Geophys. Res.-Ocean., 112, C05048, doi:10.1029/2006JC004018, 2007.

Zenk, W., Klein, B., and Schroder, M.: Cape Verde Frontal Zone, Deep-Sea Res. Pt. A, 38, Supplement 1, S505-S530, 1991.

Zhang, Z., Wang, W., and Qiu, B.: Oceanic mass transport by mesoscale eddies, Science, 345, 322-324, 2014. 